\title{
Housing Collateral, Consumption Insurance and Risk Premia: an Empirical Perspective.
}

\author{
Hanno Lustig and Stijn Van Nieuwerburgh* \\ University of Chicago/NBER and NYU Stern
}

February 16, 2004

\begin{abstract}
In a model with housing collateral, the ratio of housing wealth to human wealth shifts the conditional distribution of asset prices and consumption growth. A decrease in house prices reduces the collateral value of housing, increases household exposure to idiosyncratic risk, and increases the conditional market price of risk. Using aggregate data for the US, we find that a decrease in the ratio of housing wealth to human wealth predicts higher returns on stocks. Conditional on this ratio, the covariance of returns with aggregate risk factors explains eighty percent of the cross-sectional variation in annual size and book-to-market portfolio returns. Keywords: Asset Pricing, Risk Sharing.
\end{abstract}

${ }^{*}$ First version August 2002. The authors thank Thomas Sargent, Robert Hall, Dirk Krueger, Steven Grenadier, Narayana Kocherlakota, Andrew Abel, Fernando Alvarez, Andrew Atkeson, Patrick Bajari, John Cochrane, Timothey Cogley, Harold Cole, Marco Del Negro, Lars Peter Hansen, John Heaton, Christobal Huneuus, Kenneth Judd, Sydney Ludvigson, Sergei Morozov, Lee Ohanian, Monika Piazzesi, Luigi Pistaferri, Esteban Rossi-Hansberg, Kenneth Singleton, Laura Veldkamp, Pierre-Olivier Weill, Amir Yaron, the editor Robert Stambaugh and an anonymous referee. We also benefited from comments from seminar participants at Duke University, Stanford GSB, University of Iowa, Université de Montreal, New York University Stern, University of Wisconsin, University of California at San Diego, London Business School, London School of Economics, University College London, University of North Carolina, Federal Reserve Bank of Richmond, Yale University, University of Minnesota, University of Maryland, Federal Reserve Bank of New York, Boston University, University of Pennsylvania Wharton, University of Pittsburgh, Carnegie Mellon University GSIA, Northwestern University Kellogg, University of Texas at Austin, Federal Reserve Board of Governors, University of Gent, UCLA, University of Chicago, Stanford University, the 2003 NBER Asset Pricing Meeting in Cambridge, the Society for Economic Dynamics Meeting in New York, and the North American Meeting of the Econometric Society in Los Angeles. For help with the data, we thank Kenneth French, Chris Lundblad, and Savina Rizova. Stijn Van Nieuwerburgh acknowledges financial support from the Stanford Institute for Economic Policy research and the Flanders Fund for Scientific Research. 


\section{Introduction}

House price fluctuations play an important role in explaining the time-series and cross-sectional variation in asset returns. Given the magnitude of the housing market this is unsurprising. This paper shows that the way in which housing affects asset returns is through the role of housing as a collateral asset.

We identify a novel collateral channel that transmits shocks in the housing market to risk premia. In a model with collateralized borrowing and lending, the ratio of housing wealth to human wealth, the housing collateral ratio, changes the conditional distribution of consumption growth across households. When the collateral ratio is low, the dispersion of consumption growth across households is more sensitive to aggregate consumption growth shocks and this raises the market price of aggregate risk.

This paper focuses on connecting the model to asset price data. The predictions of the model are confirmed by US equity return data over time and in the cross-section. US investors seem to demand a larger risk compensation in times when the housing collateral ratio is low, because the housing collateral ratio predicts aggregate stock returns. In the cross-section, the model predicts that assets whose returns are more tightly correlated with aggregate consumption growth shocks when collateral is scarce trade at a discount. Conditional on the housing collateral ratio, the covariance of returns with aggregate consumption growth shocks explains about eighty percent of the cross-sectional variation in US stock returns, because the returns of value stocks are more correlated with aggregate consumption growth shocks during low collateral periods than are growth stocks.

In the model there are two main channels that transmit shocks originating in the housing market to the risk premia in asset markets. First and foremost, a drop in the housing collateral ratio adversely affects the risk sharing that enables households to insulate consumption from labor income shocks. The distribution of consumption growth fans out as this ratio decreases. When housing prices decrease, collateral is destroyed and households are more exposed to idiosyncratic labor income risk. The risk associated with these collateral constraints contributes a risk factor to the stochastic discount factor.

Second, households want to hedge against rental price shocks or consumption basket composition shocks when the utility function is non-separable in non-durable consumption and housing services. This introduces a new risk factor which is the focus of recent work by Piazzesi, Schneider, \& Tuzel (2002) and Yogo (2003). In particular, if housing services and consumption are complements then households command a larger risk premium if returns and rental price growth 
are positively correlated. Dunn \& Singleton (1986) and Eichenbaum \& Hansen (1990) report substantial evidence against the null of separability in a representative agent model with nondurable consumption and durables, but they conclude that introducing durables does not help in reducing the pricing errors for stocks.

The collateral effect does not hinge on the non-separability of preferences. Nevertheless, we incorporate non-separability in the model to isolate the non-separability effect from the collateral mechanism. Instead, it relies on imperfect consumption insurance among households induced by occasionally binding collateral constraints. Without these collateral constraints our model collapses to the standard consumption-based capital-asset-pricing model of Lucas (1978) and Breeden (1979). That model prices only aggregate consumption growth risk and it has been rejected by the data (e.g. Hansen \& Singleton (1983)). Our paper addresses two empirical failures of the consumption-based capital-asset-pricing model (CCAPM).

First, because US aggregate consumption growth is approximately i.i.d., the CCAPM implies a market price of risk that is approximately constant. However, in the data, stock market returns are predictable and this suggests that the market price of aggregate risk varies over time (e.g. Fama \& French (1988), Campbell \& Shiller (1988), Ferson, Kandel, \& Stambaugh (1987), Whitelaw (1997), Lamont (1998), Lettau \& Ludvigson (2003) and Campbell (2000) for an overview). Our model delivers time variation in the market price endogenously through the housing market. As the housing collateral ratio decreases, the conditional volatility of the liquidity factor increases. In the data, the housing collateral ratio does predict the aggregate US stock market return, mainly at lower frequencies.

Second, the covariance of asset returns with consumption growth explains only a small fraction of the variation in the cross-section of stock returns of firms sorted in portfolios according to size (market capitalization) and value (book-value to market-value ratio) characteristics (Fama \& French (1992)). ${ }^{1}$ Our model generates large value premia for stocks whose dividends are more sensitive to the housing collateral ratio. In the data, the collateral model explains eighty percent of the variability in annual returns of the Fama-French size and book-to-market portfolios. For annual returns, this matches the empirical success of the Fama \& French (1993) three-factor model and recent conditional consumption-based asset pricing models (e.g. Lettau \& Ludvigson (2001b)). The estimated market price of consumption growth risk is positive and significant,

\footnotetext{
${ }^{1}$ In response to this failure, Fama \& French (1993) directly specify the stochastic discount factor as a linear function of the market return, the return on a small minus big firm portfolio, and a high minus low book-to-market firm portfolio. The empirical success of this three-factor model has motivated quite some more recent research on the underlying macroeconomic sources of risk for which their factors proxy (e.g. Bansal, Dittmar, \& Lundblad (2002), Lettau \& Ludvigson (2001b), Santos \& Veronesi (2001) and Cochrane (2001) for an overview).
} 
while an increase in the collateral ratio lowers the estimated price of consumption growth risk, as predicted by the theory.

We measure the aggregate stock of housing collateral in three different ways: the value of outstanding mortgages, the value of residential real estate (structures and land) and the value of residential fixed assets (structures). The housing collateral ratio, which we label $m y$, is measured as the deviation from the cointegration relationship between the value of the aggregate housing stock and aggregate labor income. Housing is by far the most important collateral asset for households. In the US, two-thirds of households own their house. For the medianwealth homeowner, home equity represents seventy percent of household net worth (Survey of Consumer Finance, 1998). Residential real estate wealth accounts for twenty-eight percent of total household net worth and sixty-eight percent of non-financial assets, while home mortgages make up sixty-four percent of household liabilities (Flow of Funds, Federal Reserve, averages for 1952-2002). Currently, the value of residential wealth exceeds the total household stock market wealth (\$13.6 trillion) and the mortgage market is the largest credit market in the US (\$6.1 trillion).

Our model contains the following essential ingredients. It is an endowment economy with a continuum of agents who are subject to labor income shocks. As in Lustig (2001), we allow households to forget their debts. The new feature of our model is that each household owns part of the housing stock. Housing provides utility services and collateral services. When a household chooses to forget its debts, it loses all its housing wealth but its labor income is protected from creditors, and the household is not excluded from trading. This gives rise to collateral constraints whose tightness depends on the abundance of housing collateral. We measure this by the housing collateral ratio: the ratio of collateralizable housing wealth to non-collateralizable human wealth.

The stochastic discount factor contains a new component which we label the aggregate liquidity shock (see Lustig (2001)). It is the growth rate of a cross-sectional moment of the consumption share distribution. The household's consumption share of the total endowment, both for non-durables and housing services, increases whenever the household switches to a state with a binding constraint. When a large fraction of households is constrained this growth rate is high. We call this a liquidity shock. The housing collateral ratio changes the conditional moments of the aggregate liquidity shock. When the housing collateral ratio is low, households run into binding collateral constraints more frequently. This increases the conditional standard deviation of the aggregate weight shock, and, by the same token, the market price of risk. Thus, endogenous movements in the housing collateral ratio turn the liquidity shocks in the stochastic discount factor on and off, and this induces heteroskedasticity and counter-cyclicality in the 
Sharpe ratio. This collateral mechanism is a novel feature of the model.

In Lustig \& VanNieuwerburgh (2003) we fully calibrate and solve the model. The equilibrium aggregate liquidity shock is a function of the primitives of the model: the preferences, the household endowment process, the aggregate endowment process and the aggregate rental price process. The model generates large, time-varying risk premia and a value premium for stocks whose dividends are more responsive to collateral ratio shocks.

Our empirical strategy is to estimate the stochastic process for the aggregate weight shocks. In a first step we allow this process to depend in a non-linear fashion on the aggregate pricing factors. We estimate the parameters from the moment conditions implied by the Euler equations for the aggregate market return, the risk-free rate, a long term bond and a limited number of size and book-to-market portfolios. The Euler inequalities for the representative agent allow us to precisely estimate the coefficient of risk aversion. The estimated coefficients of relative risk aversion are plausible (between 2 and 5) and much lower than those for the other models we consider, as shown by Figure 1. In addition, the parameters in the aggregate weight shock specification are estimated precisely and have the sign predicted by the collateral channel. The pricing errors are small and the model cannot be rejected.

The linear specification for the aggregate weight shock fits the data best and it allows us to make contact with the linear factor models in empirical finance. This specification delivers a conditional version of the CCAPM with the housing collateral ratio as the conditioning variable. The housing collateral ratio summarizes the investor's time-varying information set. This model prices the 25 Fama-French size and book-to-market portfolios surprisingly well by imputing the value premium to risk compensation for a higher consumption growth beta of value returns in times when collateral is scarce. We provide evidence on dividend dynamics that potentially explains why value returns respond differently to aggregate shocks when the collateral ratio is small. $^{2}$

We organize the paper as follows. In section 1, we briefly discuss other related literature. Section 2 describes the essence of the model. The third section discusses the composition channel and collateral channel in more depth. Section 4 contains the time-series predictability results and sections 5 and 6 contain the empirical results for the cross-section. Section 7 concludes. Appendix A contains technical remarks about the estimation and a more detailed description of the data. The most important figures and tables appear in the main text, all others in Appendix B.

\footnotetext{
${ }^{2}$ Our model generates significantly larger premia for claims to dividend processes that are highly sensitive to collateral shocks (Lustig \& VanNieuwerburgh (2003)).
} 


\section{Related Literature}

Our paper is closest to the work of Lettau \& Ludvigson (2001b). We also develop a scaled version of the CCAPM. Our state variable $m y$ summarizes information about future returns on housing relative to human capital while the scaling variable in Lettau \& Ludvigson (2001b) is the consumption-wealth ratio, which summarizes household expectations about future returns on the entire market portfolio.

In a different class of models, Cogley (2002) and Brav, Constantinides, \& Gezcy (2002) find that including higher moments like the standard deviation and skewness of the consumption growth distribution reduces the size of Euler equation errors for stock returns. This evidence is consistent with our model. In case of a large aggregate weight shock, the dispersion of the consumption growth distribution increases, while its skewness decreases. This provides indirect evidence for the consumption growth distribution shocks that drive our results. We provide a theory of what governs these shocks.

Cochrane (1996) explores the explanatory power of residential and non-residential investment for equity returns in the context of his production-based asset pricing framework (Cochrane (1991a)). Li, Vassalou, \& Xing (2002) find that investment growth, including household sector investment which is largely residential, can help account for a large fraction of the cross-sectional variation in equity returns. Similarly, Kullmann (2002) uses returns on residential and commercial real estate to improve the performance of the capital asset pricing model. Finally, life-cycle and portfolio choice models with housing such as Krueger \& Villaverde (2001), Cocco (2000), Yao \& Zhang (2002), Flavin \& Yamashita (2002) posit an exogenous price process for housing and consider a limited menu of traded assets. We endogenize the price of the asset but we abstract from life-cycle considerations.

\section{Model}

Our economy's risk sharing technology is subject to shocks originating in the housing market and these shocks determine the size of the wedge between the market's valuation of payoffs and the representative agent's IMRS. The stochastic discount factor in our model is

$$
m_{t+1}=m_{t+1}^{a} g_{t+1}^{\gamma},
$$

where $m_{t+1}^{a}$ is the IMRS of a representative agent who consumes non-durable consumption and housing services, and $g_{t+1}^{\gamma}$ is the liquidity factor contributed by the solvency constraints. 
This factor can be interpreted as the aggregate cost of the solvency constraints. When these solvency constraints do not bind, the liquidity factor disappears and payoffs can be priced off the representative agent's IMRS $m_{t+1}^{a}$. We show that this liquidity factor can explain some of the variation in US stock returns over time and in the cross-section.

\section{A. Endowments and Preferences}

In our economy a continuum of agents are endowed with claims to stochastic labor income streams. These agents consume non-durable consumption and housing services. We use $s^{t}$ to denote the history of events $s^{t}=\left(y^{t}, z^{t}\right)$, where $y^{t}$ denotes the history of idiosyncratic events and $z^{t}$ denotes the history of aggregate events. $\left\{c_{t}^{a}\left(z^{t}\right)\right\}$ denotes the aggregate endowment stream of non-durable consumption and $\left\{h_{t}^{a}\left(z^{t}\right)\right\}$ denotes the aggregate endowment of housing services. The evolution of the non-housing/housing expenditure ratio, defined as:

$$
r_{t}\left(z^{t}\right)=\frac{c_{t}^{a}\left(z^{t}\right)}{\rho_{t}\left(z^{t}\right) h_{t}^{a}\left(z^{t}\right)}
$$

where $\rho_{t}$ denotes the rental price of housing services, governs the relative supply of housing services in this economy.

The endowment processes are Markovian. The growth rate $\lambda_{t}\left(z^{t}\right)$ of aggregate non-durable consumption $\left\{c_{t}^{a}\left(z^{t}\right)\right\}$ only depends on the current aggregate state $z_{t}$ and the expenditure ratio is Markov in $z_{t}$ and $r_{t-1}$. Finally, the household's labor endowment share $\widehat{\eta}_{t}\left(y_{t}, z_{t}\right)$, as a fraction of the aggregate non-durable endowment $c_{t}^{a}\left(z^{t}\right)$, depends only on the current realization of the idiosyncratic shock $y_{t}$ and the aggregate shock $z_{t}$.

Preferences are standard. The households rank stochastic consumption streams according to usual criterion:

$$
U(\{c\},\{h\})=\sum_{s^{t} \mid s_{0}} \sum_{t=0}^{\infty} \delta^{t} \pi\left(s^{t} \mid s_{0}\right) u\left(c_{t}\left(s^{t}\right), h_{t}\left(s^{t}\right)\right),
$$

where $\delta$ is the time discount factor and the power utility kernel is defined over a CES-composite consumption good:

$$
u\left(c_{t}, h_{t}\right)=\frac{1}{1-\gamma}\left[c_{t}^{\frac{\varepsilon-1}{\varepsilon}}+\psi h_{t}^{\frac{\varepsilon-1}{\varepsilon}}\right]^{\frac{(1-\gamma) \varepsilon}{\varepsilon-1}},
$$

$\psi>0$ converts the housing stock into a service flow and $\varepsilon$ is the intratemporal elasticity of substitution between non-durable consumption and housing services. ${ }^{3}$

\footnotetext{
${ }^{3}$ The preferences belong to the class of homothetic power utility functions of Eichenbaum \& Hansen (1990).
} 


\section{B. Markets}

The markets for housing services are frictionless in that the ownership of the asset and the use of its services are completely distinct. Households can purchase housing services $\left\{h_{t}\left(s^{t}\right)\right\}$ in the spot markets at spot prices $\left\{\rho_{t}\left(z^{t}\right)\right\}$ as well as non-durable consumption $\left\{c_{t}\left(s^{t}\right)\right\}$.

Although the households cannot sell claims to their labor income stream $\left\{\eta_{t}\left(s^{t}\right)\right\}$, they can trade a complete set of contingent claims to insure against idiosyncratic labor income risk, but these trades are subject to solvency constraints. The solvency constraints can be stated as a restrictions on the value of a household's consumption claim, net of its labor income claim:

$$
\Pi_{s^{t}}\left[\left\{c_{t}\left(s^{t}\right)+\rho_{t}\left(z^{t}\right) h_{t}\left(s^{t}\right)\right\}\right] \geq \Pi_{s^{t}}\left[\left\{\eta_{t}\left(s^{t}\right)\right\}\right],
$$

where $\Pi_{s^{t}}\left[\left\{d_{t}\left(s^{t}\right)\right\}\right]$ denotes the price of a claim to $\left\{d_{t}\left(s^{t}\right)\right\}$.

The supply of housing wealth relative to human wealth governs the tightness of the solvency constraints. The effectiveness of the risk sharing technology our economy is endowed with depends on the ratio of the housing wealth to total wealth. We call this ratio the housing collateral ratio my:

$$
m y_{t}\left(z^{t}\right)=\frac{\Pi_{z^{t}}\left[\left\{\rho h^{a}\right\}\right]}{\Pi_{z^{t}}\left[\left\{c^{a}\right\}\right]}
$$

Suppose the households in this economy derive no utility from housing services, then there is no collateral in this economy and $m y$ is zero. All the solvency constraints necessarily bind at all nodes and households are in autarchy. As my increases, perfect risk sharing becomes feasible.

Shocks to $m y$ change the conditional distribution of consumption across households and asset prices, but this mechanism is only quantitatively interesting if the expenditure ratio $r$ or rental prices $\rho$ are subject to large, persistent shocks that significantly change my:

$$
m y_{t}\left(z^{t}\right)=\frac{\Pi_{z^{t}}\left[\left\{\frac{c^{a}}{r}\right\}\right]}{\Pi_{z^{t}}\left[\left\{c^{a}\right\}\right]}
$$

and this is borne out by the data. All of these processes are highly autocorrelated. Table I reports the $\mathrm{AR}(1)$ coefficients for the log expenditure ratio and the log rental price of housing services.

The housing collateral ratio is high today when the expenditure ratio $r$ is low today, or if $\epsilon$ is smaller than one, when the rental price $\rho$ is high, and the effect on $m y$ grows as the persistence of $r$ increases. In the model, the aggregate housing collateral ratio my, the current expenditure

Special cases are separability $\left(1-\gamma=\frac{\epsilon-1}{\epsilon}\right)$ and Cobb-Douglas preferences $(\epsilon=1)$. 
ratio and the rental price are all quasi-sufficient statistics for the risk sharing capacity of this economy. In equilibrium the stock of collateral is allocated efficiently across households in a stationary equilibrium and this absolves us from the need to track the entire distribution of collateral across households. The next section explains exactly how shocks to my impinge on allocations and prices.

\section{Equilibrium Consumption}

In equilibrium household consumption follows a strikingly simple pattern: as long as a household does not switch to a state in which the solvency constraint binds, or, equivalently, net wealth is zero, the household's consumption as a fraction of total consumption decreases, but when the household enters a state with zero net wealth, its consumption share jumps up. ${ }^{4}$ The size of these jumps for the latter and the rate of consumption share decline for the former class of households depends on the housing collateral ratio my. When the ratio is low, the cutoff consumption shares at which at the household solvency constraint binds increase. As a result, the other households will experience steeper declines in their consumption shares.

We use consumption weights $\omega$ to characterize the equilibrium prices and allocations. $\widetilde{\omega}_{t}\left(\omega, s^{t}\right)$ is the new consumption weight of a households that enters the period with consumption weight $\omega$. These consumption weights are constant as long as the agent does not switch to a state with a binding constraint, but when it does, its new weight $\widetilde{\omega}_{t}\left(\omega, s^{t}\right)$ is set to a cutoff weight $\underline{\omega}_{t}\left(y_{t}, z^{t}\right)$. To compute the aggregate consumption weight, we integrate over the new household weights at aggregate node $z^{t}: \xi_{t}^{a}\left(z^{t}\right)=\int \widetilde{\omega}_{t}\left(\omega, s^{t}\right) d \Phi_{t}\left(\omega ; z^{t}\right) . \Phi_{t}\left(\cdot ; z^{t}\right)$ is the distribution over weights at the start of period $t$ and this distribution depends on the entire aggregate history $z^{t}$. The actual consumption share of an agent equals the ratio of his individual stochastic consumption weight to the aggregate consumption weight:

$$
c_{t}\left(\omega, s^{t}\right)=\frac{\widetilde{\omega}_{t}\left(\omega, s^{t}\right)}{\xi_{t}^{a}\left(z^{t}\right)} c_{t}^{a}\left(z^{t}\right) \text { and } h_{t}\left(\omega, s^{t}\right)=\frac{\widetilde{\omega}_{t}\left(\omega, s^{t}\right)}{\xi_{t}^{a}\left(z^{t}\right)} h_{t}^{a}\left(z^{t}\right)
$$

$\xi_{t}^{a}\left(z^{t}\right)$ is a non-decreasing stochastic process. These risk sharing rules clear the markets for non-durable consumption and housing services by construction. At the end of the period we store the household's consumption share $\omega=\frac{\widetilde{\omega}_{t}\left(\omega, s^{t}\right)}{\xi_{t}^{a}\left(z^{t}\right)}$ as its identifying label. The cutoff levels for the consumption weights increase as the housing collateral ratio decreases. When there is no housing collateral at all, the cutoff level for the consumption share equals the household's labor

\footnotetext{
${ }^{4}$ When a household is not in a state with a binding constraint today, it may still face a binding constraint in some state tomorrow.
} 
income share:

$$
\frac{\underline{\omega}_{t}\left(y_{t}, z^{t}\right)}{\xi_{t}^{a}\left(z^{t}\right)}=\nearrow \widehat{\eta}\left(y_{t}, z_{t}\right) \text { as } m y \searrow
$$

where $\widehat{\eta}\left(y_{t}, z_{t}\right)$ is the labor income share relative to the total non-durable endowment. The lower the collateral ratio, the larger the increase in its consumption share when it switches to a state with a binding solvency constraint. Household consumption becomes increasingly sensitive to income shocks as the housing collateral ratio decreases, illustrated in figure 2 .

In a stationary equilibrium, each household's consumption share is drifting downwards as long as it does not switch to a state with a binding constraint. The rate at which these shares decrease is $\log \left(g_{t}\right) \equiv \Delta \log \left(\xi_{t}^{a}\right)$. This rate depends on the housing collateral ratio. When this ratio is low, the solvency constraints are tight, many households are highly constrained and the remainder experience large consumption share drops. The risk-free rate is low, inducing households to decrease assets at a high rate. When this ratio is high enough, none of the households are constrained and interest rates are high. The growth rate of the aggregate weight process $\log \left(g_{t}\right)$ determines the consumption growth of the unconstrained households and these households price payoffs in each state of the world. That is the focus of the next section.

\section{The Market Price of Aggregate Risk}

Using the risk sharing rules in (3), the following expression for the intertemporal marginal rate of substitution (IMRS) of the unconstrained household emerges: $m_{t+1}=m_{t+1}^{a} g_{t+1}^{\gamma}$. This is the stochastic discount factor (SDF) in the sense of (Hansen \& Jagannathan (1991)) that prices payoffs. The first section focusses on $m^{a}$ and it examines the data through the lens of a representative agent model. The new risk factor contributed by the non-separability in the utility function is referred to as composition risk. We show that the market price of composition risk is likely to be small. The second section focusses on $g_{t+1}$ and it examines the liquidity risk factor contributed by the collateral channel more carefully.

\section{A. Composition Effect}

Without the collateral constraints, ours is a representative agent economy. If utility is nonseparable, the housing market introduces a novel risk factor: shocks to the non-housing expenditure share. The representative agent's marginal utility growth is determined by aggregate 
consumption growth and non-housing expenditure share growth:

$$
m_{t+1}^{a}=\delta\left(\frac{c_{t+1}^{a}}{c_{t}^{a}}\right)^{-\gamma}\left(\frac{\alpha_{t+1}}{\alpha_{t}}\right)^{\frac{\varepsilon-\frac{1}{\gamma}}{\gamma}(\varepsilon-1)}
$$

where $\alpha_{t}$ is the non-housing expenditure share, $\gamma$ is the coefficient of relative risk aversion and $\varepsilon$ is the intratemporal elasticity of substitution between housing services and non-durable consumption. Composition risk is small. Piazzesi et al. (2002) show that only values for the elasticity of intratemporal substitution $\varepsilon$ close to but slightly larger than one, and low values for the intertemporal elasticity deliver a volatile SDF, at the cost of overstating the volatility of rental price growth by a factor ranging from 3 when $\varepsilon$ is 1.05 to 15 when $\varepsilon$ is 1.01 . In addition, this composition effect generates little or no variation in the conditional Sharpe ratio's on risky assets.

\section{B. Liquidity Effect and the Collateral Channel}

We now focus on the case of separable utility. The representative agent's IMRS $m^{a}$ is the aggregate consumption growth rate raised to the power $-\gamma$ and the SDF reduces to:

$$
m_{t+1}=\delta\left(\frac{c_{t+1}^{a}}{c_{t}^{a}}\right)^{-\gamma} g_{t+1}^{\gamma}
$$

For the liquidity effect to increase the volatility of the SDF, the liquidity factor needs to be negatively correlated with aggregate consumption growth. There are two features that deliver a negative correlation between aggregate consumption growth and the aggregate liquidity shock: (1) an increase in the cross-sectional dispersion of labor income shocks, and (2) a decrease in the amount of collateral, both when aggregate consumption growth is low. The first one relies on the time series properties of labor income in the US, the second one on the time series properties of rental prices in the housing market. Both of these channels amplify the effect of aggregate consumption growth shocks on the SDF.

Dispersion of Labor Income Shocks Constantinides \& Duffie (1996) build a negative correlation between the dispersion of consumption growth across households and aggregate stock returns in their model to generate large risk premia, drawing on earlier work by Mankiw (1986). The first channel in our model is a different version of this (see Lustig (2001)). It delivers a negative correlation between the standard deviation of the consumption growth distribution and 
stock returns, but this correlation is the equilibrium outcome of the interaction between the solvency constraints and the time series properties of the labor income process. A larger fraction of agents draws higher labor income shares $\widehat{\eta}(y, z)$ when aggregate consumption growth is low and, as a result of the persistence of labor income shocks, higher cutoff levels $\widetilde{\omega}_{t}\left(\omega, s^{t}\right)$. This increases the size of the aggregate weight shock in low aggregate consumption growth states. There is some empirical support for this channel. Storesletten, Telmer, \& Yaron (2003) conclude that the volatility of idiosyncratic labor income shocks in the US more than doubles in recessions.

Collateral Supply Shocks If the rental price of housing services declines in response to a negative aggregate consumption growth shocks, liquidity shocks will tend to be larger when aggregate consumption growth is low, because the destruction of collateral tightens the solvency constraints. Table I lists the results of regressing log rental prices on aggregate consumption growth and lagged rental prices. In the US rental prices do increase in response to a positive aggregate consumption growth shock in the post-war sample. Over the entire sample the evidence is mixed.

Time-Varying Market Price of Risk The housing collateral ratio governs the amount of risk sharing that can be sustained and variations in the ratio endogenously generate heteroskedasticity in the SDF. Low housing collateral ratios coincide with a high conditional volatility of the SDF, because a large fraction of households will be severely constrained in case of an adverse aggregate consumption growth shock. This mechanism leaves a huge footprint in the crosssectional standard deviation of consumption growth, plotted in Figure 3.

The next section concentrates on measuring the US housing collateral ratio directly. Our measure reveals a surprising amount of historical variation that is consistent with the variation in US stock returns.

\section{Time Series Evidence}

In testing the model, we chose to measure the housing collateral ratio $m y$ directly, simply because forces outside our model probably influence housing prices. In the model, both the housing collateral ratio and the rental price or the expenditure share are valid state variables. The first section concentrates on its measurement. The second section confronts our measure with stock returns. 


\section{A. Measuring the Housing Collateral Ratio}

$m y$ is defined as the ratio of collateralizable housing wealth to non-collateralizable human wealth. In the model only the total supply of collateral matters, not the precise way in which it is allocated across households, because the available collateral is used where the demand for insurance is highest. ${ }^{5}$ We can safely abstract from the distribution of collateral across households. Still, human wealth is unobserved. Following Lettau \& Ludvigson (2001a), we assume that the nonstationary component of human wealth $H$ is well approximated by the non-stationary component of labor income $Y$. In particular, $\log \left(H_{t}\right)=\log \left(Y_{t}\right)+\epsilon_{t}$, where $\epsilon_{t}$ is a stationary random process. The assumption is valid in a model in which the expected return on human capital is stationary (see Jagannathan \& Wang (1996) and Campbell (1996)).

Housing Collateral We use three distinct measures of the housing collateral stock $H V$ : the value of outstanding home mortgages $(\mathrm{mo})$, the market value of residential real estate wealth $(r w)$ and the net stock current cost value of owner-occupied and tenant occupied residential fixed assets $(f a)$. The first two time series are from the Historical Statistics for the US (Bureau of the Census) for the period 1889-1945 and from the Flow of Funds data (Federal Board of Governors) for 1945-2001. The last series is from the Fixed Asset Tables (Bureau of Economic Analysis) for 1925-2001.

We use both the value of mortgages $H V^{m o}$ and the total value of residential fixed assets $H V^{r w}$ to allow for changes in the extent to which housing can be used as a collateral asset, and we use both $H V^{r w}$, which is a measure of the value of housing owned by households, and $H V^{f a}$ which is a measure of the value of housing households live in, to allow for changes in the home-ownership rate over time. Appendix A provides detailed sources. Real per household variables are denoted by lower case letters. The real, per household housing collateral series $h v^{m o}, h v^{r w}, h v^{f a}$ are constructed using the all items CPI from the BLS, $p^{a}$, and the total number of households, $N$, from the Bureau of the Census.

Income Aggregate income is labor income plus net transfer income. Nominal data are from the Historical Statistics of the US for 1926-1930 and from the National Income and Product Accounts for 1930-2001. Consumption and income are deflated by $p^{c}$ and $p^{a}$ and divided by the number of households $N$.

\footnotetext{
${ }^{5}$ In reality any given households may be constrained in terms of access to consumption insurance by the remaining equity in its own house, but that is not a feature of our model, as was pointed by an anonymous referee.
} 
Cointegration Log, real, per household real estate wealth $(\log h v)$ and labor income plus transfers $(\log y)$ are non-stationary. According to an augmented Dickey-Fuller test, the null hypothesis of a unit root cannot be rejected at the 1 percent level. This is true for all three measures of housing wealth $(h v=m o, r w, f a)$.

If a linear combination of $\log h v$ and $\log y, \log \left(h v_{t}\right)+\varpi \log \left(y_{t}\right)+\chi$, is trend stationary, the components $\log h v$ and $\log y$ are said to be stochastically cointegrated with cointegrating vector $[1, \varpi, \chi]$. We additionally impose the restriction that the cointegrating vector eliminates the deterministic trends, so that $\log \left(h v_{t}\right)+\varpi \log \left(y_{t}\right)+\vartheta t+\chi$ is stationary. A likelihood-ratio test (Johansen \& Juselius (1990)) shows that the null hypothesis of no cointegration relationship can be rejected, whereas the null hypothesis of one cointegration relationship cannot. This is evidence for one cointegration relationship between housing collateral and labor income plus transfers. Table II reports the results of this test and of the vector error correction estimation of the cointegration coefficients:

$$
\left[\begin{array}{c}
\Delta \log \left(h v_{t}\right) \\
\Delta \log \left(y_{t}\right)
\end{array}\right]=\alpha\left[\log \left(h v_{t}\right)+\varpi \log \left(y_{t}\right)+\vartheta t+\chi\right]+\sum_{k=1}^{K} D_{k}\left[\begin{array}{c}
\Delta \log \left(h v_{t-k}\right) \\
\Delta \log \left(y_{t-k}\right)
\end{array}\right]+\varepsilon_{t} .
$$

The $K$ error correction terms are included to eliminate the effect of regressor endogeneity on the distribution of the least squares estimators of $[1, \varpi, \vartheta, \chi]$. The housing collateral ratio $m y$ is measured as the deviation from the cointegration relationship:

$$
m y_{t}=\log \left(h v_{t}\right)+\hat{\varpi} \log \left(y_{t}\right)+\hat{\vartheta} t+\hat{\chi}
$$

The OLS estimators of the cointegration parameters are superconsistent: They converge to their true value at rate $1 / T$ (rather than $1 / \sqrt{T}$ ). The superconsistency allows us to use the housing collateral ratio $m y$ as a regressor without need for an errors-in-variables standard error correction.

We also estimate the constant and trend in the cointegrating relationship while imposing the restriction $\varpi=-1$. This is the second block of each panel in table II. For $m o$ and $f a$, we find strong evidence for one cointegrating relationship. The coefficient on $\log y_{t}$ is precisely estimated (significant at the 1 percent level, not reported), varies little between subperiods, and the 95 percent confidence interval contains -1. The resulting time-series are stationary. The null hypothesis of a unit root is rejected for mymo and $m y f a$. For each subperiod, the correlation between the residual estimated assuming $\varpi=-1$ and the one with $\varpi$ freely estimated is higher than 0.95. For $r w$, the evidence for a cointegrating relationship is weaker, except for 
the 1925-2002 period. Furthermore, the slope coefficient in the cointegration relationship varies considerably between subperiods and does not contain -1 in its 95 percent confidence interval. The correlation between the residual estimated assuming $\varpi=-1$ and the one with $\varpi$ freely estimated is 0.81 for the entire sample, 0.88 for 1925-2002 and 0.89 for the post-war period.

For consistency we impose $\varpi=-1$ on all three of these series. The housing collateral ratios are labelled mymo, myrw and my fa. For the common sample period 1925-2001, the correlation between mymo and myrw is 0.89, 0.76 between mymo and myfa and 0.86 between myrw and myfa. Figure 4 displays my between 1889 and 2002. All three series exhibit large persistent swings. They reach a maximum deviation in 1932-33. Residential wealth and residential fixed assets are 30 and 34 percent above their respective joint trends with human wealth. Mortgage debt is 53 percent above its trend. The series reach a minimum in 1944-45, when mymo is -.92 , myrw is -.57 and $m y f a$ is -.38 . mymo and myrw have increased considerably since the year 2000: from .24 to .36 and from 0.19 to 0.30 respectively. Figure 5 shows the cointegration residuals $m y$ for that post-war period. Housing collateral wealth fluctuates within 30 percent below and above the long-run trend with human wealth.

In the model $m y$ is the ratio of two asset prices and hence always positive. Our empirical measure is the deviation from a cointegration relationship and therefore occasionally negative. To put the model and the data on the same footing, we rescale the housing collateral ratio: $\widetilde{m y}_{t}=m y^{\max }-m y_{t}$. The rescaled housing collateral measures collateral scarcity and is always positive. In the remainder of the paper, $m y^{\max }$ is the sample maximum in 1925-2002 (which coincides with the sample maximum in the 1889-2002 sample). The only exception is when we explicitly ask the question: If only post-war data were available, what would the housing collateral model predict for the time series and cross-section of returns?

The next section provides some evidence that the housing collateral ratio predicts stock returns before we look at the cross-section of stock returns.

\section{B. Time-Series Predictability}

In the model the market price for aggregate risk increases when housing collateral is scarce. We document this positive relationship for the US market return at longer horizons. In addition, we show that an increase in collateral scarcity predicts higher spreads on future value minus growth returns, especially at horizons of less than five years: these stocks carry a higher risk premium in bad times with little housing collateral. The cross-sectional results will shed light on why this is. 
Market Return and Fama-French Benchmark Portfolios We use the cum-dividend return on Standard and Poor's composite stock price index, denoted $R_{t}^{v w}$. The market return is expressed in excess of a risk-free rate, the return on six-month prime commercial paper. The returns are available for the period 1889-2001 from Robert Shiller's web site. In addition, we create spreads on the basis of the six Fama-French benchmark portfolios, and we look at the predictability of these spreads. The Fama-French benchmark portfolios are rebalanced annually using two independent sorts, on size (market equity) and book-to-market (the ratio of book equity to market equity). The returns are available for the period 1926-2002 from Kenneth French's web site.

Long Horizon Predictability The $K$-year continuously compounded log return on the market is defined as $r_{t+K, v w}^{K}=\left(r_{t+1, v w}^{1}+\ldots+r_{t+K, v w}^{1}\right)$ where $r_{t, v w}^{1}$ equals $\log \left(1+R_{t}^{v w}\right) . r_{t+K, v w}^{e, K}$ is the log return on the market less the log return on the riskless asset over the same holding period $K$. Figure 6 shows the housing collateral ratio (mymo) and the annualized ten-year excess return. The series exhibit a negative correlation of -0.52 .

In addition, we project long-horizon excess returns on the rescaled housing collateral ratio $\widetilde{m y}$. Row 1 of table III reports the least squares coefficient estimate on the housing collateral ratio in the regression of holding period returns on the collateral ratio:

$$
r_{t+K, v w}^{e, K}=b_{0}+b_{m y} \widetilde{m y}_{t}+e_{t+1}
$$

We consider two samples. The first panel reports the 1889-2002 results. The second panel reports the results for the 1926-2002 sample, the longest sample for which all three collateral measures are available. The standard errors on $b_{m y}$ are the HAC Newey-West standard errrors with lag length $K{ }^{6}{ }^{6}$ We also report the $p$-value of a two-sided test of the no-predictability null computed by bootstrapping. The procedure consists of estimating the slope coefficients in this predictability regression on simulated returns and collateral ratios under the null of no predictability. The p-value is computed as the fraction of slope estimates above our least squares estimate. $^{7}$

\footnotetext{
${ }^{6} \mathrm{~A}$ VAR analysis shows that the innovations in $m y$ and unpredicted returns have correlation close to zero. Therefore, there is no persistent regressor bias, see Stambaugh (1999).

${ }^{7}$ We estimate an $\operatorname{AR}(2)$ for the housing collateral ratio. The least squares coefficients for the long-horizon predictability regression are computed off simulated cumulative returns and collateral ratios. Under the null of no predictability, the one-year return is unforecastable and the $K$-period returns follow an MA(K) process with mean equal to the $K$-period average return. We sample i.i.d. errors for the collateral ratio and the one-year return processes and recursively build up the cumulative return and collateral ratio series. We estimate 20,000 long-horizon regressions and count how many of the bootstrap slope estimates are above the least squares slope
} 
All of the slope coefficients $b_{m y}$ are positive, except for the coefficients obtained using the fixed assets measure of housing collateral $m y f a$ at short horizons. A low housing collateral ratio (high $\widetilde{m y}$ ) predicts a high future risk premium as predicted by the model. In the case of mymo, the mortgage-based housing collateral measure, the $R^{2}$ of the least-squares regression increases to 26 percent for the entire sample (row 3, first panel) and 33 percent for the shorter sample (row 3, second panel). Over the postwar-sample only the mortgage-based collateral measure mymo and the expenditure share $\alpha$, also a valid state variable, predict returns on the market. ${ }^{8}$

According to the theory, our collateral measures should also predict the spreads on value minus growth portfolios. Table IV looks at the predictability of longer holding period spreads between value and growth portfolios. We run the same regression as before but now $r_{t+K}^{s p_{i, j}}$ is the spread in $\log K$-holding-period returns for two extremum portfolios $i$ and $j$ formed on the basis of the six Fama French Benchmark Portfolios. The coefficients have the right sign for all collateral measures: the scarcer housing collateral becomes, the larger the spread on value minus growth portfolios. This is consistent with our findings in the cross-sectional pricing exercise: value stock are riskier in times characterized by a low housing collateral measure. As a result, an increase in $\widetilde{m y}$ should predict a larger spread in the longer horizon returns on value stocks. At short horizons of less than five years the null of no predictability is rejected at the 10 percent level for all three collateral measures, both for small and big firms. The results become less significant at longer horizons. This provides evidence that the collateral ratio predicts returns even at shorter horizons of less than five years.

\section{Cross-sectional Evidence: Non-Linear Factor Model}

We use returns on stock portfolios sorted by size and value characteristics, bond returns and the return on a risk-free asset to test our model. Size and book-to-market value are asset characteristics that challenge the standard CCAPM. Historically, small firm stocks and high book-to-market firm stocks have had much higher returns. In the post-war period, the size premium has largely disappeared, but the value premium is still prominent. The value premium -the average return difference between the lowest and the highest book-to-market decile- is 5.7 percent over the entire sample.

estimate. This is the p-value for the null of no predictability.

${ }^{8}$ Not reported, but available upon request. 
Size and Book-to-Market Portfolios A total of twenty-five portfolios of NYSE, NASDAQ and AMEX stocks are grouped each year into five size bins and five value (book-to-market ratio) bins. Size is market capitalization at the end of June. Book-to-market is book equity at the end of the prior fiscal year divided by the market value of equity in December of the prior year. Portfolio returns are value-weighted. The stock returns are available for the period 1926-2001 from Kenneth French's web site and are described in more detail in Fama \& French (1992). We also include the market return $R^{v w}$, the value-weighted return on all NYSE, AMEX and NASDAQ stocks. The bond return is the annual holding period return on a 10-year government bond (from CRSP). All returns are expressed in excess of an annual return on a one-month Treasury bill rate (from Ibbotson Associates). The first column of table V shows mean and standard deviation for the 26 excess returns. For comparison, the table also lists the mean and standard deviation of equally-weighted returns and the book-to-market ratio of each portfolio.

\section{A. Measuring the Liquidity Factor}

In the model, the aggregate weight shock depends on the entire history of aggregate shocks $z^{\infty}$ and $m y_{0}$. To solve the model numerically, we rely on an approximation of $g\left(z^{\infty}, m y_{0}\right)$, the growth rate of the aggregate weight process, using a truncated history of aggregate shocks and the current $m y_{t} \cdot{ }^{9}$

To bring the model to the data, we take a similar approach and use a flexible, non-linear function of the relevant state variables to parameterize the investor's forecast of aggregate weight growth:

$$
\log \left(g_{t}\left(z_{t}^{\infty}, m y_{0}\right)\right) \simeq \phi\left(F_{t}^{a}, F_{t-1}^{a}, \ldots, F_{t-k}^{a} ; m y_{t}\right)
$$

where $F_{t}^{a}$ denotes the vector of aggregate factors $F_{t+1}^{a}=\left(\Delta \log \left(c_{t+1}^{a}\right), \Delta \log \left(\alpha_{t+1}\right)\right)^{\prime}$, consisting of aggregate consumption growth and expenditure share growth. We use GMM to identify the function $\phi$ in addition to the structural parameters from the moment conditions:

$$
E_{t}\left[m_{t+1}^{a} \exp \left(\gamma * \phi\left(F_{t+1}^{a}, F_{t}^{a}, \ldots, F_{t-k}^{a} ; m y_{t+1}\right)\right) R_{t+1}^{j}\right]=1
$$

where $R_{t+1}^{j}, j=1, \ldots, n$ are the returns on the test assets. In addition, the theory imposes two kinds of inequality constraints: (1) $\phi\left(F_{t+1}^{a}, F_{t}^{a}, \ldots, F_{t-k}^{a} ; m y_{t+1}\right) \geq 0$ and (2) $E_{t}\left[m_{t+1}^{a} R_{t+1}^{j}\right] \leq 1$ that further restrict the set of feasible parameters. (1) follows from the fact that $\xi_{t}^{a}\left(z^{t}\right)$ is a non-

\footnotetext{
${ }^{9}$ This is discussed in Lustig \& VanNieuwerburgh (2003). These approximations work well, because the supply of collateral is distributed efficiently across households. The percentage forecast error has a natural interpretation: it equals the percentage deviation between aggregate consumption and the aggregate endowment.
} 
decreasing process and this immediately implies (2). The second set of inequality constraints will prove useful in identifying the structural parameter $\gamma \cdot{ }^{10}$

\section{B. Non-Linear Factor Model and GMM}

We use Chebyshev orthogonal polynomials to approximate the non-linear $\phi$-function. The advantage is that the different terms of the polynomial have the usual interpretation as linear pricing factors (Chapman (1997)).

Moment Restrictions The first moments are the average pricing errors for the test asset returns and the risk-free rate:

$$
E\left[m_{t+1} R_{t+1}^{j}-1\right]=0
$$

The theory tells us that the aggregate weight shock is exactly equal to one when the constraints do not bind and strictly greater than one in all other periods. First, we impose parametric restrictions on the polynomial such that $\phi\left(F_{t}^{a}, F_{t-1}^{a}, \ldots, F_{t-k}^{a} ; m y_{t}\right)=0$ when $m y$ equals $m y^{\max }$. In particular, we restrict ourselves to functions of the form $\phi(\cdot)=\left(m y^{\text {max }}-m y_{t}\right) *$ $\widetilde{\phi}\left(F_{t}^{a}, F_{t-1}^{a}, \ldots, F_{t-k}^{a}\right){ }^{11}$

Second, we impose the inequality restrictions $E\left[m_{t+1}^{a} R_{t+1}^{i}-1\right] \leq 0$ on the representative agent's Euler equations by adding the Kuhn-Tucker moment conditions to the standard moment conditions:

$$
\lambda(\theta) E\left[m_{t+1}^{a} R_{t+1}^{j}-1\right]=0
$$

We adopt the penalty function approach by parameterizing the Lagrangian multiplier $\lambda$ as $\exp \left(c E\left[m_{t+1}^{a} R_{t+1}^{j}-1\right]\right)$ for a positive penalty parameter $c$. To solve saddle point problems numerically, the shadow price of a binding constraint is usually approximated by the product of the penalty parameter and the constraint violation (see Judd (1998) theorem 4.7.1.) The algorithm prescribes that the penalty parameter be increased until convergence is achieved. The parameter $\gamma$ is the exponent on both components of the SDF. Without these inequality constraints, $\gamma$ is not separately identified.

In a first pass, we estimate the model using four test assets. In a second stage, we add size and value portfolios to the set of test assets.

\footnotetext{
${ }^{10}$ Luttmer (1991) exploits such restriction to derive Hansen-Jagannathan bounds in an environment with solvency constraints .

${ }^{11}$ We cannot allow the aggregate weight shock to be a function of aggregate consumption growth in isolation, because that would preclude identification of $\gamma$.
} 
Results with Four Test assets First, we estimate our model using only four test assets: the risk-free rate, the value weighted market return, the 10 year bond return and the return on a portfolio that goes long in value and short in growth (the Fama-French benchmark portfolio $R^{H M L}$ ). We use annual real, gross holding period returns from 1926 until 2002 (77 observations). ${ }^{12}$ There are four standard moment conditions and four Kuhn-Tucker moment conditions, adding up to a total of eight moment conditions. We use the identity matrix as a weighting matrix.

The Chebyshev polynomial $\widetilde{(} \cdot)$ is restricted to be first order: It contains a constant and the aggregate pricing factor, $\phi(\cdot)=\theta^{1}\left(m y^{\max }-m y_{t}\right)+\theta^{2}\left(m y^{\max }-m y_{t}\right) F_{t}^{a}$. This restriction is tested in the next subsection. We estimate the model for separable preferences: $F^{a}$ is aggregate consumption growth. The coefficient estimates in table VI lend support to the collateral channel. The positive estimate for $\hat{\theta}_{1}$ implies that periods with less collateral coincide with a high value for the aggregate weight shock and SDF. The negative estimate for $\hat{\theta}_{2}$ implies that, when aggregate consumption growth is below average (the rescaled consumption growth is negative), the aggregate weight shock is large. This effect increases as collateral becomes scarcer (higher $\left.m y^{\max }-m y_{t}\right)$. This is the collateral effect predicted by the model.

Table VI also shows how the coefficient estimates converge as the penalty parameter $c$ is increased (reading from left to right in table). Interestingly, for high penalty parameters, the inequality restrictions are satisfied and we obtain low risk aversion estimates. The representative agent's Euler inequalities rule out high $\gamma$ estimates. Finally, when the penalty parameter is increased, $\theta_{2}$ is estimated more precisely. The average pricing errors are small (the J-stat decreases) and the null hypothesis that all pricing errors are zero cannot be rejected (p-value on last line).

Results with Seven Test Assets Next, we use a more extensive set of seven test assets: a three month T-bill, a 10 year government bond, the value weighted aggregate stock market and the four extreme size and value portfolios S1B1, S1B5, S5B1, and S5B5. With the corresponding inequality conditions this adds up to a total of fourteen moment conditions.

We estimate the collateral model under separable and non-separable preferences. To investigate the effect of non-linearities we vary the order of the Chebyshev polynomial from 1 to 3 . The left panel of table VII reports the estimates for the collateral model with separable preferences. In the first order specification of the aggregate weight shock (column 1) all coefficients are estimated precisely and the point estimates are not very different from the ones we reported

\footnotetext{
${ }^{12}$ Results for quarterly data for 1952.1:2002.4 are discussed in section VI.
} 
in the case of four test assets. This model dominates the ones with higher order polynomial terms (columns 2 and 3) on the basis of a likelihood ratio test, a Wald test and a Lagrange multiplier test. The null hypothesis that all higher order polynomial coefficients are zero cannot be rejected. ${ }^{13}$ The right panel of table VII shows the results for non-separable preferences. The growth rate of the non-durable expenditure share $\Delta \log \alpha_{t+1}$ is an additional aggregate factor in the aggregate weight shock with loading $\theta^{3}$. The evidence for non-separability is weak: $\theta^{3}$ is measured imprecisely in columns 4-6. The first-order specification (column 4) fits the data best: All parameter estimates have the right sign and $\theta^{2}$ is significant. Furthermore, the null that all pricing errors are zero cannot be rejected for this specification. The p-value is .17 in the last row.

Comparing Pricing Errors It is informative to examine in more detail the pricing errors on the 7 test assets implied by the non-linear collateral model. Table VIII contrasts the collateral model in columns 3-5 with the standard CCAPM in column 1 and the representative agent model with non-separable preferences (HCAPM) in column 2. The pricing errors for the collateral CAPM are much smaller for all test assets. Only the pricing error on the small value portfolio (S1B5) is still significant for the collateral model with separability (Coll-CAPM 1). Under the collateral model with non-separability (Coll-CAPM 2) this error is reduced to 2.5 percent and no longer statistically different from zero. Coll-CAPM 3 in the last column allows for limited history dependence in the aggregate weight shock. It contains lagged consumption growth in $\widetilde{\phi}(\cdot)$. This specification does not produce significant improvements over the corresponding model without history dependence Coll-CAPM 1.

By contrast, the CCAPM and HCAPM do a poor job at pricing the risk free rate and the longterm bond, while massively overpricing growth portfolios and underpricing value portfolios. ${ }^{14}$

Since the higher order terms in the polynomials do not significantly improve the fit of the collateral model, we henceforth impose linearity on $\widetilde{\phi}$. This allows us to make contact with the linear factor model literature, and it also allows us to increase the number of test assets in the estimation stage.

\footnotetext{
${ }^{13}$ When the unrestricted model is the second order and the restricted model is the first order polynomial model, the p-values are : polynomial order 1 vs 2: LHR 1.00, Wald .93, LM .91 polynomial order 1 vs 3: LHR 1.00, Wald .70, LM .76. We conclude that the first order polynomial specification for the aggregate weight shock is the best fitting one.

${ }^{14}$ In addition, the estimated relative risk aversion for the CCAPM is high at 10.7. The null hypothesis tha all pricing errors are zero for the CCAPM and HCAPM are strongly rejected.
} 


\section{Cross-sectional Evidence: Linear Factor Model}

First, we assume $\widetilde{\phi}$ is linear in $\left(F_{t}^{a}, F_{t-1}^{a}, \ldots, F_{t-k}^{a}\right)$, and, second, we assume that the housing collateral ratio follows an autoregressive process $m y_{t+1}\left(m y_{t}, F_{t+1}^{a}\right)$ that interacts linearly with the aggregate factors. The innovations to the aggregate factors are the structural innovations in our model.

Aggregate Weight Shocks We propose a linear expression for $\phi(\cdot)$ :

$$
\phi\left(F_{t}^{a}, F_{t-1}^{a}, \ldots, F_{t-k}^{a} ; m y_{t}\right)=\left(m y^{\max }-m y_{t}\right) B(L)\left(F_{t}^{a}-\Upsilon\right)
$$

where $B(L)$ is a polynomial of order $k$ in the lag operator and $\Upsilon$ is the unconditional mean of the aggregate factors $F_{t}^{a}$. For now, we set $k=0$, but we test for additional history dependence in the estimation exercise by including up to four lags of the factors, $F_{t-k}^{a}$ for $k=1,2,3,4$, in $B(L)$. $B_{i j}$ denotes the coefficient on factor $i$ in lag $j$.

\section{A. Linear Factor Model and Fama-MacBeth}

The factor model for the weight shocks and the autoregressive process for $m y$ provide a complete description of the pricing model. By combining $\phi_{t+1}\left(m y_{t+1}, F_{t+1}^{a}\right)$ and $m y_{t+1}\left(m y_{t}, F_{t+1}^{a}\right)$, the stochastic discount factor can be stated in terms of the aggregate factors $F_{t+1}^{a}$ and the state variable $m y_{t}$. A first-order Taylor approximation of this expression delivers our linear factor model:

$$
m_{t+1} \approx \tilde{\delta}\left(\text { const }-\theta^{a} F_{t+1}^{a}-\theta^{c} F_{t+1}^{c}+\gamma \varepsilon_{t+1}\right),
$$

where the constraint factors $F_{t+1}^{c}$ are ${ }^{15}$ :

$$
F_{t+1}^{c}=\left(m y^{\max }-m y_{t}\right)\left(1, F_{t+1}^{a}\right)
$$

When the utility kernel is separable, the equity risk premium is determined by the conditional

\footnotetext{
${ }^{15}$ The associated factor loadings are:
}

$$
\begin{aligned}
\theta^{a} & =\left(\gamma-\gamma(1-\rho) B_{10} m y^{\max }, \frac{-\varepsilon+\frac{1}{\gamma}}{\frac{1}{\gamma}(\varepsilon-1)}-\gamma(1-\rho) B_{20} m y^{\max }\right) \\
\theta^{c} & =\left(\gamma \rho\left(B_{10} \Upsilon_{c}+B_{20} \Upsilon_{\rho}\right),-\gamma \rho B_{10},-\gamma \rho B_{20}\right)
\end{aligned}
$$


covariance of its returns with consumption growth and a state-varying market price of risk:

$$
\begin{array}{r}
E_{t}\left[R_{t+1}^{e, j}\right] \approx \tilde{\delta} R_{t}^{f} \gamma\left[\left(1+\Upsilon_{c}\right)^{-1}-B_{10} \gamma(1-\rho) m y^{\max }-B_{10} \rho\left(m y^{\max }-m y_{t}\right)\right] \\
\operatorname{Cov}_{t}\left(\Delta \log c_{t+1}^{a}, R_{t+1}^{e, j}\right)
\end{array}
$$

where $R_{t}^{f}$ is the risk-free rate at time t. If $B_{10}$ is zero, the expression collapses to the standard CCAPM of Lucas (1978) and Breeden (1979). The market price of consumption risk is determined by the coefficient of relative risk aversion $\gamma$. In contrast, our theory predicts an increase in the size of the aggregate weight shock when aggregate consumption growth is low, driven by an increase in idiosyncratic risk. Consumption growth has an effect on the liquidity shock: $B_{10}<0$. When housing collateral is scarce $\left(m y^{\max }-m y_{t}\right.$ is large), the market price of consumption risk is high.

Non-separability introduces a second covariance in the risk premium equation: the covariance with expenditure share changes. If $B_{20}$ is zero, the market price of composition risk is constant. In contrast, if $B_{20}<0$, the market price of composition risk is high when housing collateral is scarce $\left(m y^{\max }-m y_{t}\right.$ is large).

Unconditional $\beta$-Representation The discount factor consists of a representative agent and a constraint component:

$$
m_{t+1}=-\theta F_{t+1}
$$

where $\theta$ is a vector of constants, $\theta=($ const, $\tilde{\theta})$ and $\tilde{\theta}=\left(\theta^{a}, \theta^{c}\right)$ and $F_{t+1}=\left(1, \tilde{F}_{t+1}\right)$. $\tilde{F}_{t+1}=\left(F_{t+1}^{a \prime}, F_{t+1}^{c \prime}\right)^{\prime}$ is a vector of representative agent and constraint risk pricing factors. The conditioning information is embedded in the scaled constraint factors while $\theta$ itself is constant.

These constraint factors contain the original aggregate factors scaled by the housing collateral ratio $m y_{t} . m y_{t}$ is the conditioning variable that summarizes the investor's information set. The model can be tested using the unconditional orthogonality conditions of the discount factor and excess asset returns $j$ :

$$
E\left[m_{t, t+1} R_{t+1}^{e, j}\right]=0 .
$$

Using the definition of the risk-free rate and the covariance, the unconditional factor model in (8) implies an unconditional $\beta$-representation:

$$
E\left[R_{t+1}^{e, j}\right]=\tilde{\delta} \bar{R}^{f} \tilde{\theta} \operatorname{Cov}\left(\tilde{F}_{t+1}, R_{t+1}^{e, j}\right)=\tilde{\lambda} \tilde{\beta}^{j}
$$


where $\bar{R}^{f}$ is the average risk-free rate, $\tilde{\beta}^{j}$ is asset $j$ 's risk exposure and $\tilde{\lambda}$ is a transformation of the parameter vector $\tilde{\theta}^{16}$ :

$$
\begin{aligned}
\tilde{\beta}^{j} & =\operatorname{Cov}\left(\tilde{F}, \tilde{F}^{\prime}\right)^{-1} \operatorname{Cov}\left(\tilde{F}, R^{e, j}\right) \\
\tilde{\lambda} & =\tilde{\delta} \bar{R}^{f} \tilde{\theta} \operatorname{Cov}\left(\tilde{F}, \tilde{F}^{\prime}\right)
\end{aligned}
$$

This unconditional $\beta$-representation is the equation we estimate using the Fama-MacBeth procedure.

Computational Procedure We apply the two-stage Fama-MacBeth procedure and estimate the unconditional $\beta$-representation $E\left[R_{t+1}^{e, j}\right]=\tilde{\lambda} \tilde{\beta}^{j}$. In a first time-series stage, for each asset $j$ separately, excess returns are regressed on factors to uncover the $\tilde{\beta}$ 's. In a second cross-sectional stage, average excess returns are regressed on the $\tilde{\beta}$ 's from the first stage to obtain the market prices of risk $\tilde{\lambda}$. Chapter 12 of Cochrane (2001) describes the procedure in more detail.

\section{B. Results for the Collateral Model}

We use all 25 size and book-to-market portfolios and the value weighted market return as test assets.

Table IX reports the estimates for the market price of risk $\tilde{\lambda}$ obtained from the second-stage of the Fama-MacBeth procedure. Below the estimates for $\tilde{\lambda}$, we report conventional standard errors and Shanken (1992) standard errors, which correct for the fact that the $\tilde{\beta}$ 's are generated regressors from the first time-series step.

Row 1 shows the standard CCAPM. It explains 9 percent of the cross-sectional variation in excess returns of the size and book-to-market portfolios between 1926 and 2002. Unsurprisingly, the coefficient of relative risk aversion $\gamma$ implied by the market price of consumption risk $\tilde{\lambda_{c}}$ is very high (22, not reported). With non-separable preferences but perfect commitment, the change in the non-durable expenditure share is an additional asset pricing factor. This is the HCAPM of Piazzesi et al. (2002). The non-separability effect increases the $R^{2}$ to 50 percent (row 2). Rows 3 through 8 investigate the collateral model. With separable preferences, the new asset pricing factors are the housing collateral ratio $m y$ and consumption growth scaled by $m y$. The fit improves to 73 - 88 percent for the respective measures of the housing collateral ratio

\footnotetext{
${ }^{16}$ Lettau \& Ludvigson (2001b) point out that $\tilde{\lambda}$ does not have a straightforward interpretation as the vector of market prices of risk. The market prices of risk $\lambda$ depend on the conditional covariance matrix of factors which is unobserved.
} 
(rows 3-5). The coefficients on the interaction terms $\lambda_{m y . c}$ are positive and significant (column $5)$. With non-separable preferences, the interaction term of $m y$ with expenditure share growth is an additional asset pricing factor (rows 6-8). The new interaction term has a positive factor loading, but does not enter statistically significantly. Except for the conditioning variable myfa, non-separability does not add much to the explanatory power of the collateral CAPM.

The intercept in the cross-sectional regression, $\tilde{\lambda}_{0}$ should be zero. Its estimate is positive and significant in rows 1 and 2, but becomes insignificant for the collateral CCAPM.

The coefficient estimates for $\tilde{\lambda}$ can be related to the structural parameters of the model, and we can infer that a decrease in the housing collateral ratio $m y_{t}$ increases the market price of consumption risk. This follows because the estimated $\tilde{\lambda}_{m y . c}$ is positive. The loadings $\tilde{\theta}$ can be backed out of the $\tilde{\lambda}$ estimates using $\tilde{\lambda}=\tilde{\theta}\left[\tilde{\delta} \bar{R}^{f} \operatorname{Cov}\left(\tilde{F}, \tilde{F}^{\prime}\right)\right]$. These factor loadings $\theta$ are listed in table $\mathrm{X}$. The loadings on the constraint factors $\theta_{1}^{c}$ and $\theta_{2}^{c}$ are positive. Assuming the persistence coefficient $\rho$ for $m y$ is positive, this implies that $B_{10}$ is negative. $B_{10}$ is the coefficient on aggregate consumption growth in the aggregate weight growth function. An adverse aggregate consumption growth shock increases the the aggregate weight shock and hence the risk premium. This is exactly the effect predicted by the theory. ${ }^{17}$ The implied $B_{20}$ estimates are negative as well (right panel of table $\mathrm{X}$ ). The conclusion is the same.

Figure 7 compares the CCAPM and the collateral-CAPM under separability. The left panel plots the sample average excess return on each of the 26 portfolios against the return predicted by the standard CCAPM. The CCAPM hardly explains any of the variation in excess returns across portfolios. The right panel, which corresponds to the estimates in row 4 of table IX, shows the returns predicted by the collateral-CAPM. Most of the size and value portfolios line up along the 45 degree line.

Table XI reports the sample average pricing errors on each of the 26 portfolios. Relative to the CCAPM, the collateral-CAPM largely eliminates the overpricing of growth stocks and the underpricing of value stocks. The root mean squared error (RMSE) across portfolios is 3.27 percent per annum for the CCAPM (first column, second to last row) but less than half as large for the collateral-CAPM (1.21 percent, last column). The errors are comparable in size and sign

\footnotetext{
${ }^{17} \mathrm{~A}$ negative consumption growth shocks has two effects. First, a recession decreases $m y$ which makes the risksharing bounds narrower. Second, a recession coincides with an increase in the income dispersion, which makes the bounds narrower as well. In either case, the extent to which a recession narrows the bounds depends on the level of $m y$ or, equivalently, the housing collateral ratio. When the risk-sharing bounds are narrower, agents run more frequently into them and the aggregate weight growth is high. When housing collateral is scarce, $m y^{\max }-m y_{t+1}$ is large. A negative consumption growth shock increases $\phi_{t+1}$ for $B_{10}<0$. When $m y_{t+1}=m y^{\max }$, there is no effect of innovations to aggregate consumption and rental price growth on the expression for the aggregate weights: $\phi_{t+1}$ is one.
} 
to the Fama \& French (1993) three-factor model (second column of table XI, see also section C). However, the pricing errors on the small growth firms (S1B1 and S1B2) and large growth and value firms (S5B1, S5B4, S5B5) are lower for the collateral model than for the three-factor model. The last row of the table shows a $\chi^{2}$-distributed test statistic for the null hypothesis that all pricing errors are zero. The collateral-CAPM is the only model for which the hypothesis of zero pricing errors cannot be rejected at the 5 percent level. ${ }^{18}$

Robustness As a first robustness check, we relax the Markov assumption that we imposed on the aggregate weight shock by including additional lags of the aggregate factors (consumption growth and expenditure share growth) in the empirical specification of the aggregate weight process. We set $k \in 1,2,3,4$ in equation (6). This introduces additional asset pricing factors in the unconditional $\beta$-representation. Table XII reports the estimation results for the sample 19292002 and collateral measure myrw. Lines 1 and 5 repeat the reults for no history dependence (lines 4 and 7 of table IX, note that the sample period is slightly different). Lines 2-4 add the interaction of the housing collateral ratio with lagged consumption growth to the set of factors for the separable model. Lines 6-8 do the same for the non-separable model. The fit of the cross-sectional estimation does not improve significantly by adding more lagged aggregate factors. The extra factors enter mostly insignificantly, while leaving the estimates on the factors from the model with no history dependence largely unchanged. Only for $k=4$ is there some additional explanatory power. We conclude that the Markov assumption in the linear collateral model fits the data well. This is consistent with our results for the non-linear model (column 5 in table VIII).

Second, the theory implies that the expenditure share $\alpha_{t}$ and the relative rental price $\rho_{t}$ are valid state variables that measure the capacity of risk-sharing in the economy. We estimate the collateral models with the expenditure share and the relative rental price as conditioning variables instead of the housing collateral ratio my. The fit, as measured by the cross-sectional $R^{2}$ or by pricing errors, is very close to the results reported in the paper for my. Again, the differences between the separable and non-separable model are small (results are available upon request).

Third, the collateral model performs well when estimated on quarterly data. The flow of

\footnotetext{
${ }^{18}$ Because of the sampling error in the regressors the Shanken correction for the $\chi^{2}$ test statistics is large. This is because the macro-economic factors have a low sample variance and the size of the standard-error correction is inversely related to this variability. While increasing the standard errors on the estimated market prices of risk, this correction reduces the $\chi^{2}$ test statistic. The result that the collateral-CAPM fails to reject the null hypothesis of zero pricing errors should be interpreted in this light.
} 
funds data needed to construct our collateral measures start in 1952.1. The value of residential fixed assets is only available through 2001.4, all other data are through 2002.4. Rows 3-8 of Table XIII shows the estimated market prices of risk for collateral model. Rows 1 and 2 show the standard CAPM and HCAPM. The CCAPM explains more of the cross-sectional variation in stock returns in the postwar sample $\left(R^{2}=.48\right)$. Irrespective of whether the collateral effect is captured using the housing collateral ratio using outstanding mortgages, the housing collateral ratio using the value of residential wealth, or the expenditure share (as described in the previous paragraph), the data support the collateral effect. The parameters have the right sign: scarcer collateral is associated with a higher market price of risk. For annual post-war data, the collateral-CAPM with separable preferences explains between 70 and 83 percent and the collateral-CAPM with non-separable preferences between 76 and 84 percent of the crosssectional variation in the 26 portfolios (results are available upon request).

Time-Varying Betas Why does the collateral-CAPM help explain the value premium? In the model, a stock's riskiness is determined by the covariance of its returns with aggregate risk factors conditional on the state variable $m y$. The conditional covariance reflects time-variation in risk premia. If time variation in risk premia is important for explaining the value premium, then stocks with high book-to-market ratios should have a larger covariance with aggregate risk factors in risky times, when $m y$ is low $\left(m y^{m a x}-m y_{t}\right.$ is high), than in less risky times, when $m y$ is high $\left(m y^{\max }-m y_{t}\right.$ is low). This is the pattern we find in the data.

We estimate the risk exposure (the $\beta$ 's) for each of the twenty-five size and book-to-market portfolios and the value weighted market return. This is the first step of the Fama-MacBeth two-step procedure. To make the point more forcefully we impose separability on the preferences over housing and non-durable consumption:

$$
R_{t+1}^{e, j}=\tilde{\beta}_{0}^{j}+\tilde{\beta}_{c}^{j} \Delta \log c_{t+1}+\tilde{\beta}_{m y}^{j}\left(m y^{m a x}-m y_{t}\right)+\tilde{\beta}_{m y . c}^{j}\left(m y^{m a x}-m y_{t}\right) \Delta \log c_{t+1} .
$$

Equation (10) allows the covariance of returns with consumption growth to vary with $m y$. For each asset $j$, we define the conditional consumption beta as $\beta_{t}^{j}=\tilde{\beta}_{c}^{j}+\left(m y^{m a x}-m y_{t}\right) \tilde{\beta}_{m y . c}^{j}$. We estimate equation (10) and compute the average consumption beta in good states, defined as times in which $m y$ is one standard deviation above zero, and in bad states (risky times) when $m y$ is one standard deviation below zero. Table XIV shows that the high book-to-market portfolios (B4 and B5) have a consumption $\beta$ that is large when housing collateral is scarce and small in times of collateral abundance. The opposite is true for growth portfolios (B1 and B2). 
Moreover, the value stocks have higher consumption betas than the growth stocks in bad states, and vice versa for the good states. This is the sense in which value portfolios are riskier than growth portfolios.

The left panel of figure 8 shows that the value portfolios (B4, B5) have a high return and the growth portfolios (B1, B2) have a low return. The right panel plots realized excess returns against $\tilde{\beta}_{m y . c}^{j}$, the exposure to the interaction term of the housing collateral ratio with aggregate consumption growth. Growth stocks in the lower left corner have a low exposure to collateral constraint risk whereas value stocks have a large exposure. So, value stocks, are riskier than growth stocks because their returns are more highly correlated with the aggregate factors when risk is high $\left(m y^{\max }-m y_{t}\right.$ is high $)$ than when risk is low $\left(m y^{\max }-m y_{t}\right.$ is low). Furthermore, there is a substantial cross-sectional variation in these betas. Because both the estimates of $\tilde{\lambda}_{m y . c}$ and of $\tilde{\beta}_{m y . c}^{j}$ are positive, value stocks are predicted to have a higher risk premium. The value premium is the compensation for the fact that high book-to-market firms pay low returns when housing collateral is scarce and constraints bind more frequently.

\section{Comparison Across Models}

The cross-sectional explanatory power of the collateral-CAPM for size and value portfolios compares favorably to other asset pricing models. We discuss model comparison in two ways. The first one presents the Fama-McBeth regressions for other models, in the same fashion we discussed the results for the collateral model. The advantage of this approach is that we can infer the structural parameters from the estimated market prices of risk. ${ }^{19}$ The second model comparison looks at spreads of portfolios that are correctly priced by our model and are predicted to have a high expected return. It asks whether the alternative models also prices these spreads. And conversely, what are the high return spreads that alternative models price correctly but fail to be priced by our model. Here we focus on size and value premia, in section (D) we look at other dimensions of cross-sectional variation in stock returns.

Fama-McBeth Regression Table XV compares return-based asset pricing models in rows 1-3 with consumption-based models in rows 4-6.

The capital asset pricing model relates the returns on stocks to their correlation with the return on the wealth portfolio. In the standard CAPM of Lintner (1965), the return on the wealth portfolio is proxied by the market return $R^{v w}$ (row 1). It explains 28 percent of annual

\footnotetext{
${ }^{19} \mathrm{~A}$ drawback of comparing models by the cross-sectional $R^{2}$ is that the mimicking portfolio of asset pricing factors may be mean-variance inefficient, see Kandel \& Stambaugh (1995).
} 
returns. Because stock market wealth is an incomplete total wealth measure, Jagannathan \& Wang (1996) include the return on human wealth in the return on the wealth portfolio. That return is measured by the growth rate in labor income (plus transfers). The $R^{2}$ in row 2 increases slightly to 37 percent. Kullmann (2002) investigates the improvements to the CAPM when residential housing wealth is incorporated into the definition of wealth. In our model housing wealth affects returns only through the collateral ratio. In the economy of Santos \& Veronesi (2001), times in which investors finance a large fraction of consumption out of labor income ( $l c$ is low), are less risky. Their conditional CAPM explains 50 percent of the annual returns (row 3$).{ }^{20}$

The Fama \& French (1993) three-factor model adds a size and a book-to-market factor to the standard CAPM. The size factor is the return on a hedge portfolio that goes long in small firms and short in big firms $(s m b)$. The value factor is the return on a hedge portfolio that goes long in high book-to-market firms and short in low book-to-market firms $(\mathrm{hml})$. This model accounts for 78 percent of the cross-sectional variation in annual returns (row 7). Given its good fit, this model serves as the empirical benchmark.

In contrast to the previous models, consumption-based asset pricing models measure the riskiness of an asset directly off the covariance with marginal utility growth. One of the objectives of this literature has been to identify macroeconomic sources of risk that can explain the empirical success of the Fama \& French (1993) size and book-to-market factors. The fourth row reports the standard CCAPM of Breeden (1979). Lettau \& Ludvigson (2001b) explore a conditional version of the CCAPM with the consumption-wealth ratio as scaling variable. The market price of consumption risk increases in times with low cay (recessions). The Lettau-Ludvigson model explains 86 percent of the annual cross-sectional variation.

Model 6 is our collateral-CCAPM under separability (as previously reported in row 4 of table IX). The model goes a long way in accounting for the cross-sectional differences in returns on the 25 Fama-French portfolios and the market return. The $R^{2}$ of 88 percent improves upon the fit of the Fama-French model.

For quarterly data, table XIII shows that the collateral model with separability prices the cross-section of size and book-to-market potfolios as well as the Lettau-Ludvigson (row 9) and Santos-Veronesi models (row 10). ${ }^{21}$

As a robustness exercise, we investigate residual explanatory power of the idiosyncratic

\footnotetext{
${ }^{20}$ The authors also investigate a scaled version of the CCAPM, as we do, but their results for the scaled CCAPM are not as strong as for the scaled CAPM.

${ }^{21}$ We use quarterly data on the consumption-wealth ratio from Martin Lettau's web page.
} 
portfolio characteristics, size (log market capitalization) and value (log value weighted book-tomarket ratio of the portfolio), for each of these 7 models. In contrast with the return-based models and the static CAPM, there are no residual size nor value effects in the collateralCCAPM. The same conclusion is found for the post-war sample. Results are available upon request.

Spreads We construct size and value spreads from the 25 size and book-to-market portfolios. For each size quintile, the value spread is defined as the difference between the highest bookto-market quintile return and the lowest book-to-market quintile return. Likewise, for each book-to-market quintile, the size spread is defined as the difference between the highest size quintile return and the lowest size quintile return.

Table XVI displays the observed value and size spreads (first column) and compares them to the spreads predicted by the various consumption-based (left panel) and return-based models (right panel).

The high return spreads with small pricing error that are identified by our model (column 2) are the value spreads V1 (smallest firms) and V5 (largest firms) and the size spreads S1, S4 and S5. With the exception of the cay-CCAPM in column 4, all other models fail to price these high return spreads. The pricing error for the other models is especially big for the value spread for small firms (V1), which is economically the most significant one. The negative size premium for growth firms (S1) is only found for the cay-CCAPM and our model. Even the Fama-French model, constructed to price these spreads, has a large abnormal return (alpha) associated with V1, V5, S1 and S5 relative to our model. Our model and the cay-CCAPM show strong similarity in the predicted pattern for the spreads. The cay-CCAPM has a larger error associated with V5 and S5. Our model has a relatively larger pricing error associated with V3, S2 and S4.

Conversely, we ask whether high return spreads predicted by other models are priced by our model. As apparent from Table XVI, the standard Consumption CAPM, the standard CAPM, the human capital augmented CAPM, and conditional CAPM, with the labor income to consumption ratio as conditioning variable, do not generate large expected returns which are priced with small errors. The Fama-French three-factor model predicts a high return on the V2 and V3 spread. The V2 spread of 6.2 percent is lower than the spread in the data (8.2 percent), V3 is higher. Our model predicts an even lower spread for V2 (4.4 percent) than the FF model. 


\section{Other Dimensions of Cross-Sectional Variation}

Sofar we have focused on explaining cross-sectional stock return variation along the size and book-to-market dimensions. Here we briefly discuss the explanatory power of the collateral model for cross-sectional return variation in momentum portfolios and portfolios sorted by dividend-price and earnings-price ratios.

Momentum Portfolios We use monthly data from Bansal, Dittmar and Lundblad for 10 momentum decile portfolios and compound them to quarterly and annual returns. We calculate the root mean squared pricing errors on the 10 momentum decile portfolios when the market prices of risk are estimated by Fama-McBeth on the 25 size and book-to-market portfolios and the 10 momentum portfolios. We also compute pricing errors using 10 size, 10 value and 10 momentum portfolios as test assets. We focus on the performance of the collateral CAPM relative to the standard CCAPM and the three-factor model.

While the pricing errors on the momentum decile portfolios are large for all three models, the pricing errors are noticeably smaller for the collateral CAPM than for the consumption CAPM or the three-factor Fama French model. This is especially true for the quarterly data (1952.1-1999.4) where the RMSE is .76 per quarter, compared to 1.2 percent for the other two models. The pricing error on the lowest momentum decile portfolio ('losers') is 2.6 percent per quarter for the CCAPM, 1.5 percent for the three-factor model and only .8 percent for the collateral CAPM. Likewise, for highest momentum decile portfolio ('winners') the pricing errors are -1.7 percent (CCAPM), -2.2 percent (FF) and -1.0 percent (Coll CAPM). For annual data on momentum portfolios (1927-1999), there still is a reduction in RMSE, but it is less pronounced (more detailed results are available upon request).

Dividend-Price and Earnings-Price Portfolios We look at 5 quintile portfolios formed by sorting on the dividend-price ratio and 5 quintile portfolios sorted by earnings-price ratio. We add these portfolios to the market return, 5 book-to-market quintile portfolios, and 5 size quintile portfolios. ${ }^{22}$ For each characteristic, a spread is defined as the difference of the two extremum quintile portfolio returns.

The data indicate a spread of 2.5 percent per year associated with the dividend yield sort. This spread is priced well by our model ( 2.3 percent), as well as by the three-factor model ( 2.7 percent).

\footnotetext{
${ }^{22}$ The dividend-price portfolio returns are available for 1926-2002. The earnings-price portfolios are available from 1952 on. All data are from Kenneth French' web site.
} 
In the post-1952 period there is a spread of 9.3 percent per year associated with the portfolio sorted by earnings-price ratio. With the exception of the Fama-French model, which predicts a 8.2 percent expected return, other models fall short of pricing this spread. Our model underprices the spread by 3.5 percent, but the unexplained return is smaller than for the CCAPM and the cay-CCAPM. The lc-conditional CAPM does a good job at pricing the dividend-price and earnings-price spreads but misprices the size and value spreads (more detailed results are available upon request).

We conclude that, relative to other models, the collateral model does well at explaining spreads on portfolios sorted by momentum, dividend yield and earnings-price ratios jointly with size and value spreads.

\section{E. Dividends on Value Portfolios}

We found that the returns of value firms are more correlated with aggregate risk in times when the housing collateral ratio is low. Here we take the next step by identifying one potential source of this pattern by examining the response of dividends to collateral shocks.

We use annual dividend data on each of the 10 portfolios sorted on book-to-market. Bookto-market is defined as book equity at the end of the prior fiscal year divided by the market value of equity in December of the prior year. We follow Bansal et al. (2002) by constructing dividends from value-weighted total returns and price appreciation rates on the decile value portfolios (both from Kenneth French). We construct nominal annual dividends by summing up monthly nominal dividends. The data are for 1952-1999.

Table XVII shows how dividends, normalized by the aggregate labor income plus transfers, of the high book-to-market portfolios (B9, B10) are low when housing collateral is scarce. They are strongly positively correlated with the housing collateral ratio. The normalized dividend process for the low book-to-market ratio portfolios is strongly negatively correlated with my (B1, b2). Using a bivariate VAR, we study the response of the normalized dividend process on the growth (B1) and value (B10) portfolios to an impulse in the housing collateral ratio. Figure 9 shows the impulse response graphs. The responses of the dividend shares to an innovation to myfa are mirror images of each other. These different cash flow responses to collateral innovations can potentially -endogenously- explain the joint distribution of returns and the collateral ratio in the US data. 


\section{Conclusion}

House price fluctuations play an important role in explaining the time-series and cross-sectional variation in asset returns. Given the magnitude of the housing market this is unsurprising. This paper shows that the way in which housing affects asset returns is through the role of housing as a collateral asset. The housing collateral mechanism endogenously generates heteroskedasticity and counter-cyclicality in the market price of risk. In Lustig \& VanNieuwerburgh (2003) we solve for the equilibrium of the model numerically, while this paper focusses on connecting the model to the data. We specify the liquidity factor in the SDF as a semi-parametric function of the housing collateral ratio and the aggregate pricing factors.

The Euler equation restrictions for the stock market return, a short-term bond, a long-term bond and a few size and book-to-market portfolios, in addition to the Euler inequality restrictions for the representative agent, yield precise, low risk aversion estimates. The estimated liquidity shocks are larger in times of low aggregate consumption growth when housing collateral is scarce, as predicted by the model. A linear version of this model prices the 25 size and book-to-market portfolios remarkably well.

Why does the collateral model work better than the standard CCAPM? The data suggest that the answer lies in allowing for time-variation in risk-sharing. The standard CCAPM implies that risk-sharing is always perfect. There is a wealth of empirical evidence against full consumption insurance at different levels of aggregation: at the household level (e.g. Attanasio \& Davis (1996) and Cochrane (1991b)), the regional level (e.g. Hess \& Shin (1998)) and the international level (e.g. Backus, Kehoe, \& Kydland (1992)). Blundell, Pistaferri, \& Preston (2002) find evidence for time-variation the economy's risk sharing capacity. In a companion paper, we provide direct empirical support for the underlying time-variation in risk-sharing (Lustig \& VanNieuwerburgh (2002)). Using US metropolitan area data, we find that the degree of insurance between regions decreases when the housing collateral ratio is low. Our theory only predicts strong consumption growth correlations when housing collateral is abundant. The data seem to support this qualification; conditioning on the housing collateral ratio weakens the consumption correlation puzzle for US regions. 


\section{Figures and Tables}

Figure 1. First and Second Moments of the Stochastic Discount Factor.

The Hansen-Jagannathan bounds are computed using annual data from 1926-2002 for the real value-weighted market return, the risk-free rate, a 10 year bond and $R^{H M L}$, the return on the high value minus low value stock portfolio. The model parameters for the consumption-CAPM, the Housing-CAPM, the Collateral-CAPM under separable preferences and the Collateral-CAPM under non-separable preferences are estimated by GMM for these 4 test assets. The plot shows the moments of the SDF, evaluated at the parameter estimates.

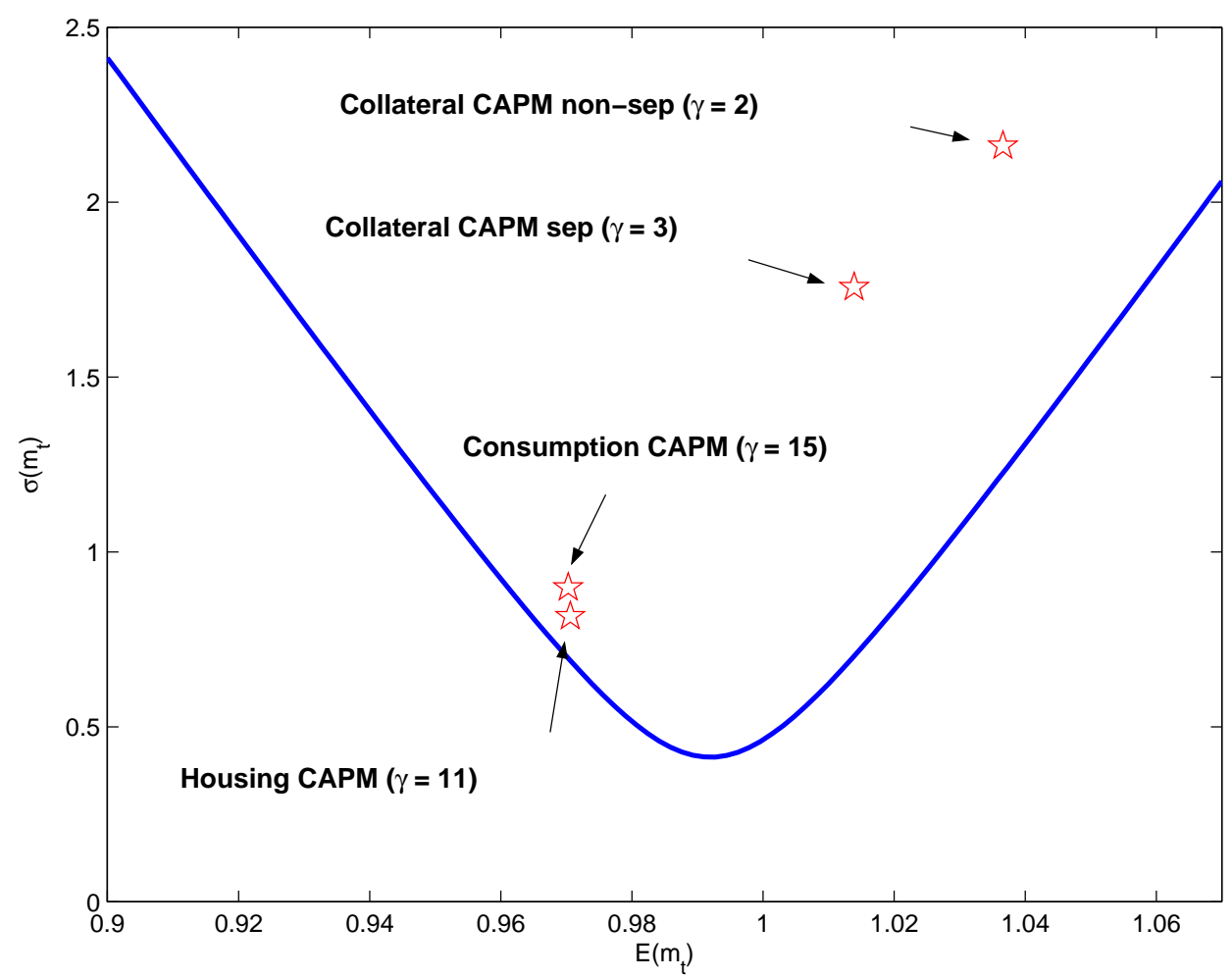


Figure 2. The Consumption Share Cutoff of One Household and the Housing Collateral Ratio. The dotted line is the housing collateral ratio and the full line is the cutoff

underlineomega $a_{t}$ which determines the optimal consumption share. The graph shows a 200 period simulation of the model at an annual frequency. The parameters are $\delta=.95, \gamma=8$ and $\varepsilon=.15$. The calibration is discussed in detail in Lustig \& VanNieuwerburgh (2003).

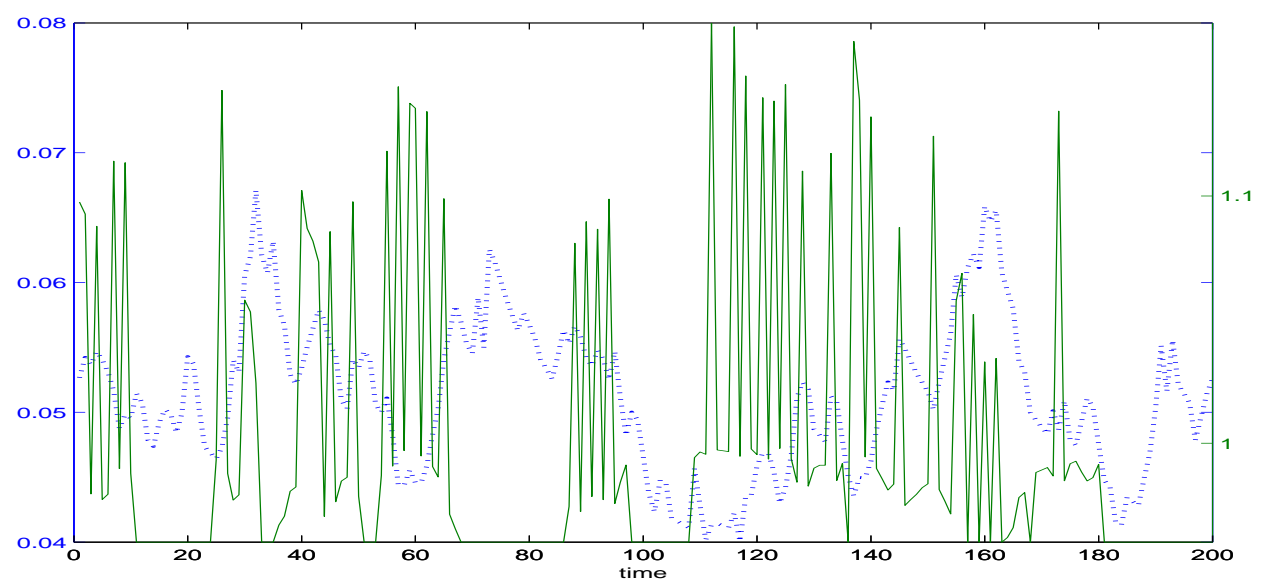

Figure 3. The Standard Deviation of Consumption Growth, Liquidity Shocks and the Housing Collateral Ratio.

The dotted line is the housing collateral ratio $m y$. The left panel plots $m y$ against the cross-sectional standard deviation of consumption growth (right axis). The right panel plots $m y$ against the aggregate liquidity shock $g$ (right axis). The graph shows a 200 period simulation of the model at an annual frequency. The parameters are $\delta=.95, \gamma=8$ and $\varepsilon=.15$. The calibration is discussed in detail in Lustig \& VanNieuwerburgh (2003).
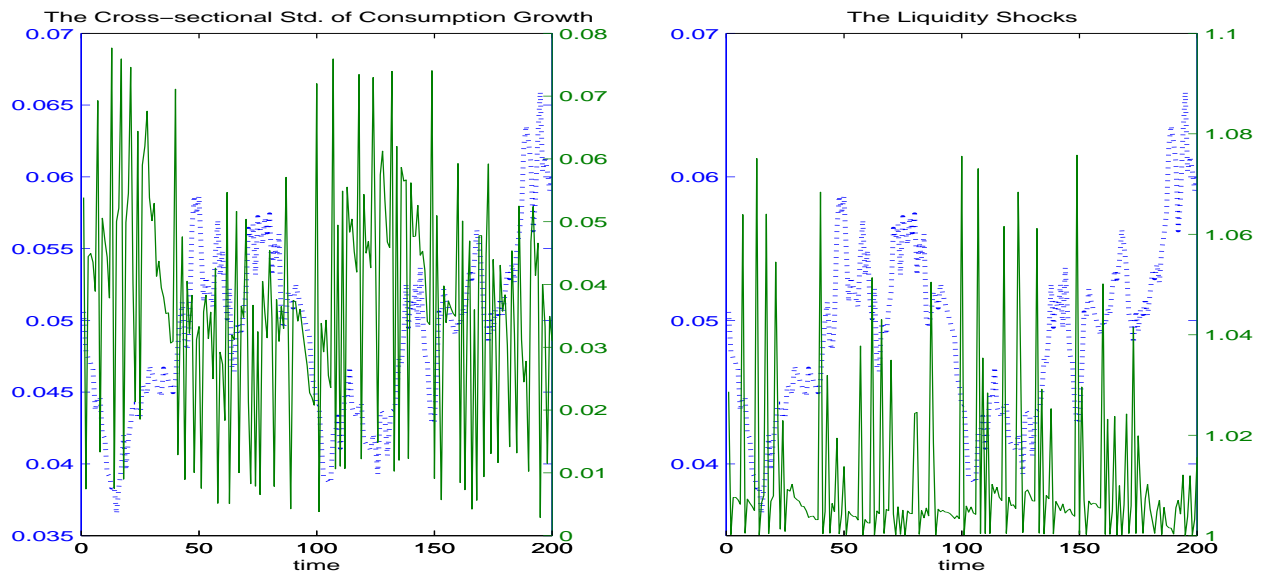
Figure 4. Estimated Housing Collateral Ratio, 1889-2002.

Deviation from the cointegration relationship between human wealth $(y)$ and outstanding home mortgages ( $m o$, full line), non-farm residential wealth ( $r w$, dashed line) and residential fixed asset wealth ( $f a$, dash-dotted line). Data are for 18892002 .

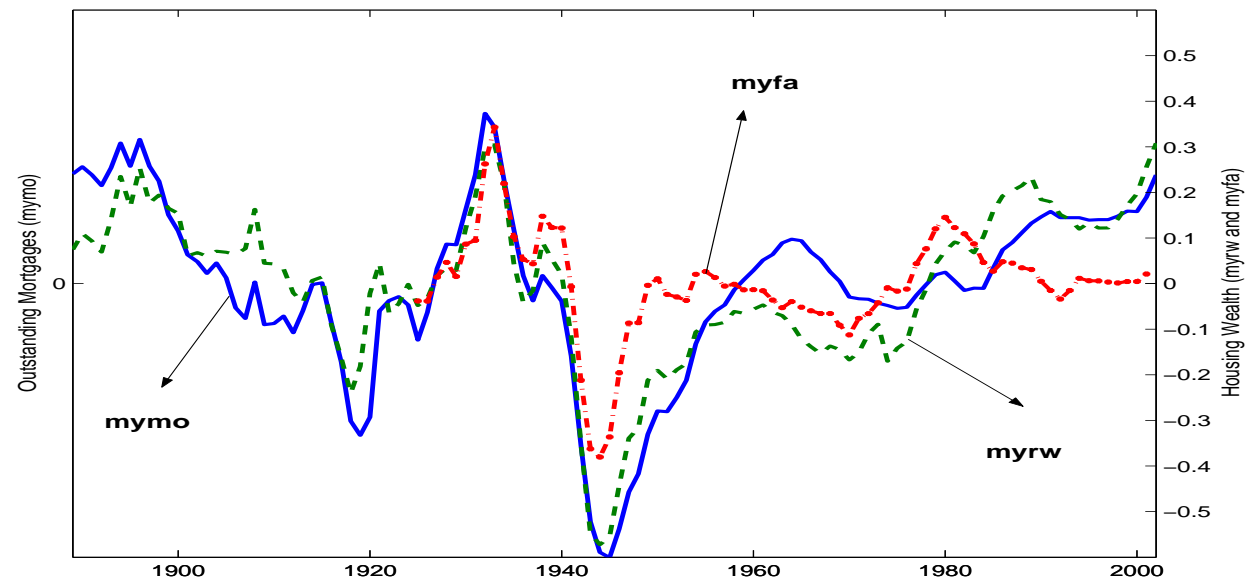

Figure 5. Estimated Housing Collateral Ratio, 1945-2002.

Deviation from the cointegration relationship between human wealth $(y)$ and outstanding home mortgages (mo, full line), non-farm residential wealth ( $r w$, dashed line) and residential fixed asset wealth ( $f a$, dash-dotted line). Data are for 19452002.

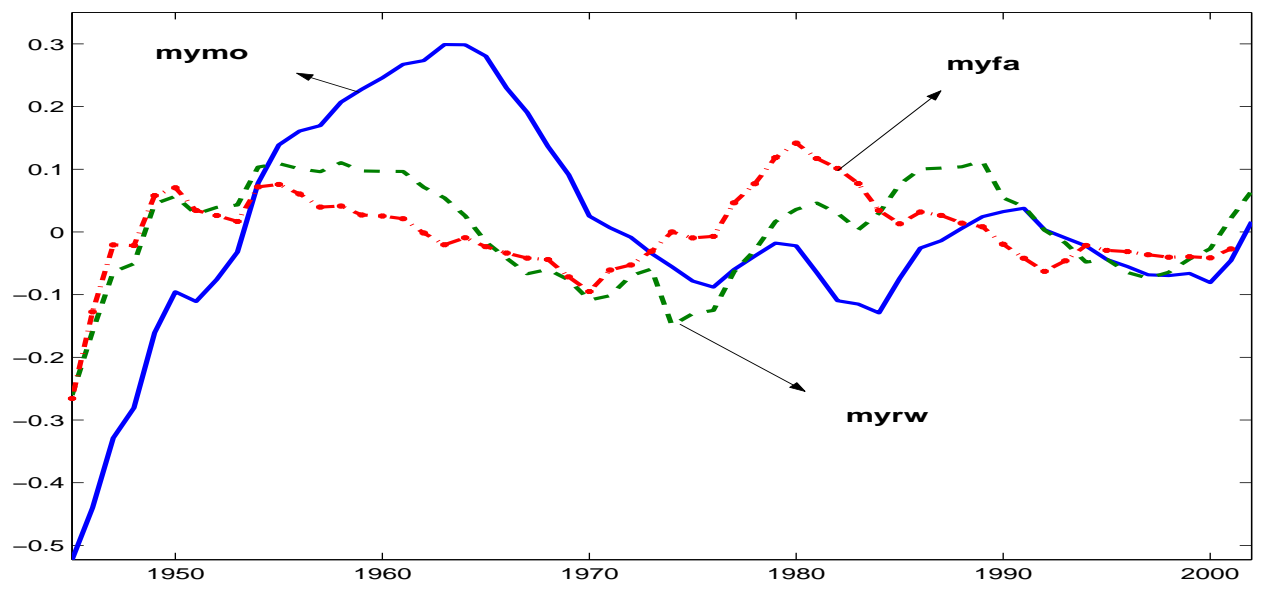


Figure 6. Ten-year Excess Market Return and the Housing Collateral Ratio. The housing collateral ratio is mymo, the measure based on outstanding mortgages

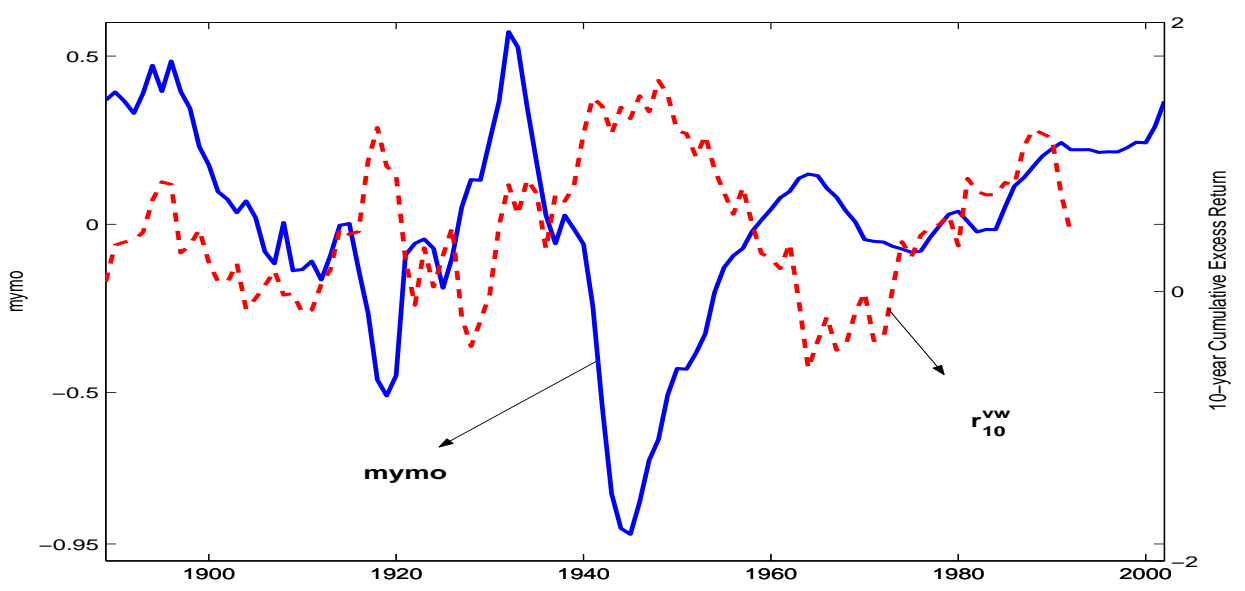

Figure 7. Realized versus Predicted Returns: The Consumption-CAPM and Collateral-CAPM. Left Panel: Realized average excess returns on 25 Fama-French portfolios and the value weighted market return against predicted excess returns by standard Consumption-CAPM. Right Panel: against predicted returns by Collateral-CAPM (under separability).
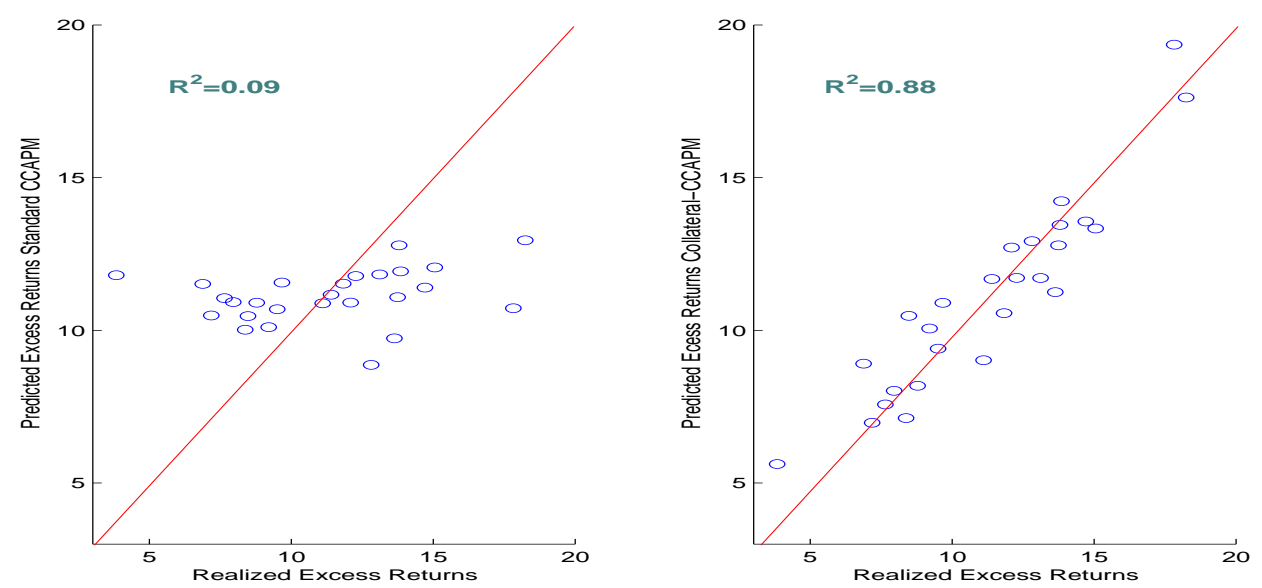
Figure 8. The Collateral CAPM and the Value Premium.

Left Panel: Realized average excess returns on 25 Fama-French portfolios and the value weighted market return against excess returns predicted by the collateral-CAPM with myrw. Right Panel: Realized average excess returns against $\widetilde{\beta}_{m y . c}$, the exposure to interaction term of $m y^{\max }-m y_{t}$ and $\Delta \log c_{t+1}$, estimated in the first-stage of the Fama-MacBeth regression.
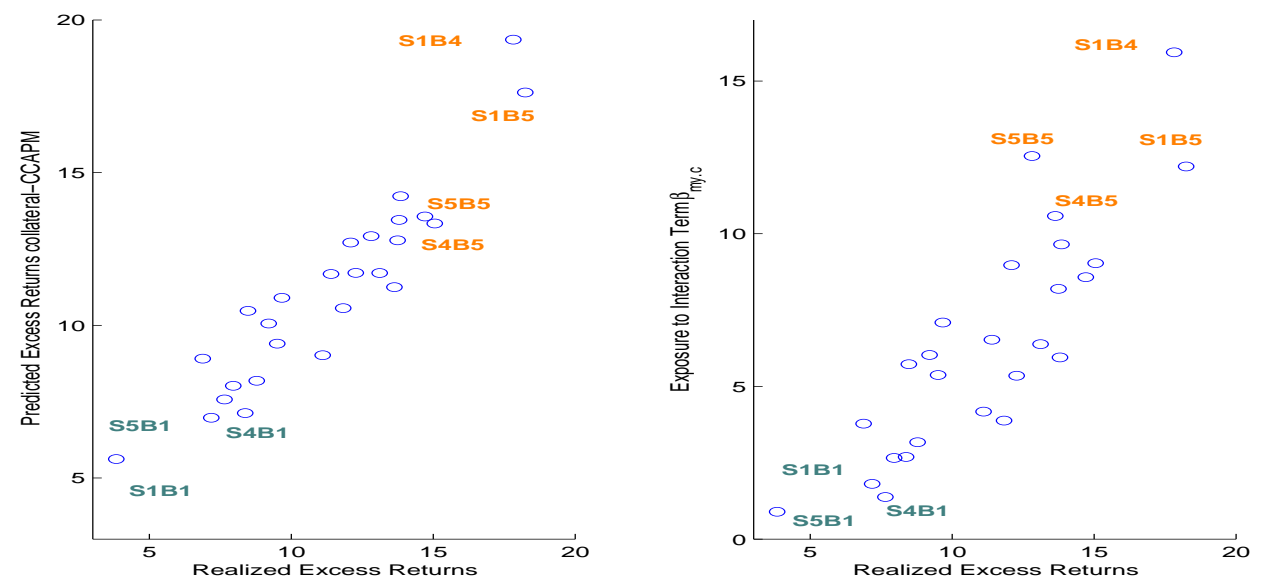

Figure 9. Response of the the log Dividend Share on Value and Growth Portfolio to Impulse in Housing Collateral Ratio.

Left panel: Response of the log dividend share on the highest value decile $(B 10)$ to a one standard deviation innovation in the housing collateral ratio myfa. Right panel: Response of the log dividend share on the lowest value decile $(B 1)$ to a one standard deviation innovation in the housing collateral ratio my fa. The underlying VAR contains the log dividend to labor income plus transfers ratio and the housing collateral ratio. The sample is 1952-2002. The dashed lines are standard errors around the responses, computed from 5,000 Monte Carlo simulations.
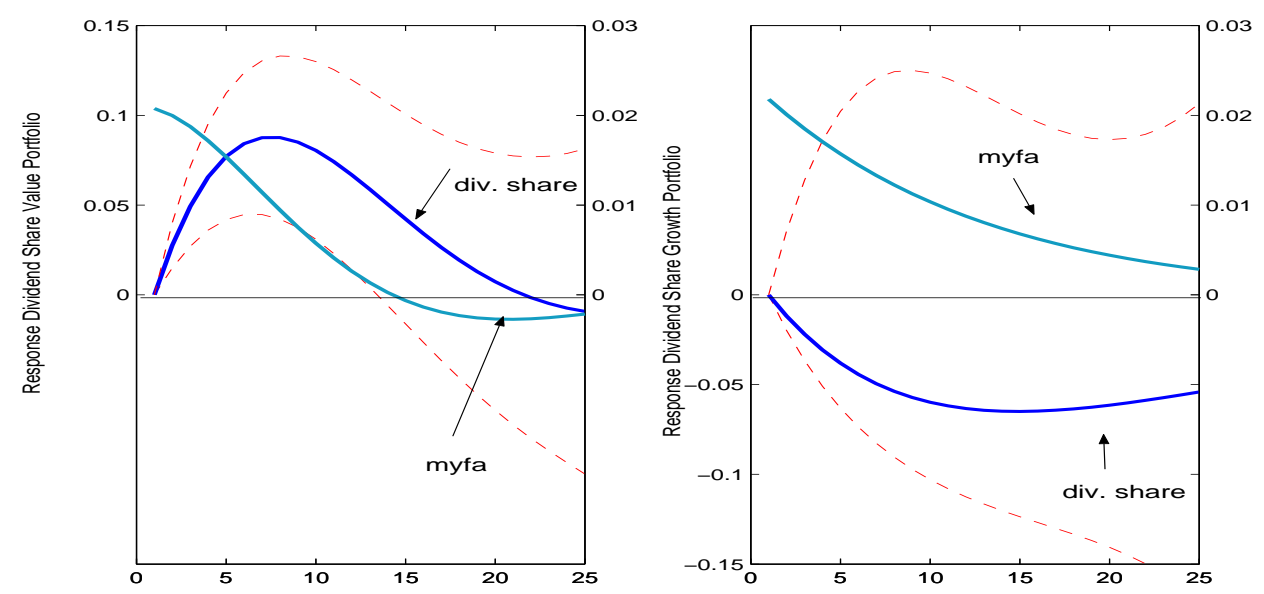
Table I

Expenditure Share and Rental Price Regression Results.

Panel A reports regression results for $\log \left(z_{t+1}\right)=\theta \log \left(z_{t}\right)+\lambda \Delta \log \left(c_{t+1}\right)+\epsilon_{t+1}$, where $z$ is the expenditure share of nondurable consumption. Panle B reports results for the regression $\log \left(\rho_{t+1}\right)=\theta \log \left(\rho_{t}\right)+\lambda \Delta \log \left(c_{t+1}\right)+\epsilon_{t+1}$, where $\rho$ is the rental price. Below the OLS point estimates are HAC Newey-West standard errors. The left panel reports the results for the entire sample, while the right panel reports the results for the post-war sample. The variables with superscript 1 are available for 1926-2002. The variables with superscript 2 are only available for 1929-2002. The data appendix contains detailed definitions and data sources for these variables.

\begin{tabular}{|c|c|c|c|c|}
\hline \multirow[t]{3}{*}{ Expl. Var. } & $\theta$ & $\lambda$ & $\theta$ & $\lambda$ \\
\hline & \multicolumn{2}{|c|}{ 1926/9-2002 } & \multicolumn{2}{|c|}{ 1945-2002 } \\
\hline & \multicolumn{4}{|c|}{ Panel A: Expenditure Share } \\
\hline $\log \left(z^{1}\right)$ & \multicolumn{2}{|c|}{.925} & $\begin{array}{c}.950 \\
(.033)\end{array}$ & \\
\hline \multirow[t]{2}{*}{$\log \left(z^{1}\right)$} & .890 & .824 & .957 & .824 \\
\hline & $(.033)$ & $(.141)$ & $(.033)$ & $(.180)$ \\
\hline \multirow[t]{2}{*}{$\log \left(z^{2}\right)$} & .940 & & .936 & \\
\hline & $(.037)$ & & $(.026)$ & \\
\hline \multirow[t]{2}{*}{$\log \left(z^{2}\right)$} & .940 & .816 & .952 & .816 \\
\hline & $(.032)$ & $(.159)$ & $(.027)$ & $(.181)$ \\
\hline \multirow[b]{2}{*}{$\log \left(\rho^{1}\right)$} & \multicolumn{4}{|c|}{ Panel B: Rental Price } \\
\hline & \multicolumn{2}{|c|}{$\begin{array}{l}.953 \\
(027)\end{array}$} & .851 & \\
\hline \multirow[t]{2}{*}{$\log \left(\rho^{1}\right)$} & .955 & .102 & .817 & .261 \\
\hline & $(.027)$ & $(.181)$ & $(.054)$ & $(.240)$ \\
\hline \multirow[t]{2}{*}{$\log \left(\rho^{2}\right)$} & .941 & & .911 & \\
\hline & $(.023)$ & & $(.046)$ & \\
\hline \multirow[t]{2}{*}{$\log \left(\rho^{2}\right)$} & .932 & -.321 & .896 & .259 \\
\hline & $(.023)$ & $(.158)$ & $(.047)$ & $(.172)$ \\
\hline
\end{tabular}




\section{Table II}

\section{Cointegration Analysis.}

The vector error-correction model of housing collateral measure $h v$ and labor income plus transfers $y_{t}$ is estimated for 1889-2002, 1925-2002, and 1945-2002 for the mortgages $(h v=m o)$ in panel A and real estaate wealth $(h v=r w)$ in panel B, and for 1925-2001 and 1945-2001 for residential fixed assets $(h v=f a)$ in panel C. The second through fourth columns show cointegration coefficient estimates: $\varpi$ for labor income $y_{t}, \vartheta$ for the time trend and $\chi$ is a constant. These are the coefficients in a regression of $\log h v$ on a constant, a time trend $t$ and labor income $y_{t}$. Coefficient estimates for autoregressive terms (8 lags) are not reported. The fifth column shows the likelihood ratio statistic of the Johansen cointegration test (constant and a trend in the cointegration relationship). The last column shows the value of the ADF test statistic ( 8 lags) of the null hypothesis of a unit root in the resulting cointegration series. For both test, significance at the $10 \%$ level is denoted by $\mathrm{a}^{*}$, significance at the $5 \%$ level by ${ }^{* *}$, and at the $1 \%$ level by ${ }^{* * *}$. The second sub-panel of each panel, labelled Restricted, imposes the restriction that $\varpi=1$.

\begin{tabular}{|c|c|c|c|c|c|}
\hline Sample Period & $\varpi$ & $\vartheta$ & $\chi$ & $L H R$ & $A D F$ \\
\hline & \multicolumn{5}{|c|}{ Panel A: Housing Wealth Measure: Mortgages mo } \\
\hline & \multicolumn{5}{|c|}{ Unrestricted } \\
\hline 1889-2002 & -1.5164 & -.0066 & 1.8010 & $21.07^{*}$ & $-3.46^{* *}$ \\
\hline $1925-2002$ & -1.2064 & -.0164 & 2.3546 & $35.04 * * *$ & $-5.38^{* * *}$ \\
\hline \multirow[t]{2}{*}{ 1945-2002 } & -1.2987 & -.0176 & 2.6511 & $30.77^{* * *}$ & $-3.06^{* *}$ \\
\hline & \multicolumn{5}{|c|}{ Restricted } \\
\hline $1889-2002$ & -1 & -.0102 & 1.6974 & & $-3.08^{* *}$ \\
\hline $1925-2002$ & -1 & -.0148 & 2.0624 & & $-4.16^{* * *}$ \\
\hline \multirow[t]{3}{*}{$1945-2002$} & -1 & -.0233 & 2.8302 & & $-2.89^{*}$ \\
\hline & \multicolumn{5}{|c|}{ Panel B: Housing Wealth Measure: Residential Wealth $r w$} \\
\hline & \multicolumn{5}{|c|}{ Unrestricted } \\
\hline 1889-2002 & -1.8255 & .0084 & -.3659 & 15.16 & $-3.46^{* *}$ \\
\hline $1925-2002$ & -.5480 & -.0120 & .1895 & $34.00^{* * *}$ & $-4.01^{* * *}$ \\
\hline \multirow[t]{2}{*}{$1945-2002$} & -.4108 & -.0147 & .3311 & $25.00^{*}$ & $-3.32^{* *}$ \\
\hline & \multicolumn{5}{|c|}{ Restricted } \\
\hline 1889-2002 & -1 & .0011 & -.4434 & & -2.29 \\
\hline $1925-2002$ & -1 & -.0023 & -.1720 & & $-3.42^{* *}$ \\
\hline \multirow[t]{3}{*}{ 1945-2002 } & -1 & -.0083 & .3784 & & $-3.51^{* *}$ \\
\hline & \multicolumn{5}{|c|}{ Panel C: Housing Wealth Measure: Fixed Assets $f a$} \\
\hline & \multicolumn{5}{|c|}{ Unrestricted } \\
\hline $1925-2001$ & -1.0137 & -.0004 & -.2257 & $52.01^{* * *}$ & $-4.70^{* * *}$ \\
\hline \multirow[t]{2}{*}{$1945-2001$} & -1.0055 & -.0011 & -.1624 & $28.45^{* *}$ & $-3.41^{* *}$ \\
\hline & \multicolumn{5}{|c|}{ Restricted } \\
\hline $1925-2001$ & -1 & -.0005 & -.2254 & & $-4.65^{* * *}$ \\
\hline $1945-2001$ & -1 & -.0026 & -.0365 & & $-2.88^{*}$ \\
\hline
\end{tabular}


Table III

\section{Long-Horizon Predictability Regressions.}

The results are for the regression $r_{t+K, v w}^{e, K}=b_{0}+b_{m y} \widetilde{m y}{ }_{t}+\epsilon_{t+K}$, where $r_{t+K, v w}^{e, K}$ are cumulative (log) excess returns on the S\&P Composite Index over a $K$-year horizon. Panel A reports results for for the full sample 1889-2002; the sample size decreases from 113 observations for $K=1$ to 104 years for $K=10$. Panel B reports the results for 1926-2002; the sample size decreases from 77 observations for $K=1$ to 68 years for $K=10$. The sub-panels report the results for the different collateral measures. Sub-panel 1 reports results for the mortgage-based collateral measure $m y m o$, sub-panel 2 for the measure based on residential wealth myrw and sub-panel 3 for the measure based on fixed assets my fa. The housing collateral ratio is rescaled so that it lies between 0 and 1 and measures collateral scarcity: $\widetilde{m y} y_{t}=\left(\frac{m y^{m a x}}{m y^{m a x}-m y_{t}}-m^{m i n}\right)$, where $m y^{\max }$ and $\operatorname{my} y^{\min }$ are the maximum and minimum observation in the respective samples. The first row of each sub-panel reports least squares estimates for $b=b_{m y}$. Newey-West HAC standard errors $\sigma^{n w}$ are reported in the second row of each sub-panel. The standard errors correct for serial correlation of order $K$, where $K$ is the holding period. The third row reports the $R^{2}$ for this OLS regression. The fourth row of each sub-panel reports the p-value of the null hypothesis of no predictability, obtained by bootstrap.

\begin{tabular}{|c|c|c|c|c|c|c|c|c|c|c|}
\hline Horizon $K$ & 1 & 2 & 3 & 4 & 5 & 6 & 7 & 8 & 9 & 10 \\
\hline & \multicolumn{10}{|c|}{ Panel A: 1889-2002 } \\
\hline & \multicolumn{10}{|c|}{ Sub-panel 1: Collateral Measure: Mortgages mymo } \\
\hline$b$ & 0.08 & 0.19 & 0.29 & 0.32 & 0.48 & 0.74 & 1.12 & 1.65 & 2.15 & 2.54 \\
\hline$\sigma^{n w}$ & 0.04 & 0.07 & 0.11 & 0.15 & 0.19 & 0.24 & 0.29 & 0.33 & 0.36 & 0.40 \\
\hline$R^{2}$ & 0.01 & 0.02 & 0.02 & 0.02 & 0.03 & 0.06 & 0.09 & 0.15 & 0.22 & 0.26 \\
\hline \multirow[t]{2}{*}{$p-v a l$} & 0.15 & 0.12 & 0.13 & 0.16 & 0.11 & 0.06 & 0.03 & 0.01 & 0.00 & 0.00 \\
\hline & \multicolumn{10}{|c|}{ Sub-panel 2: Collateral Measure: Residential Wealth myrw } \\
\hline$b$ & 0.06 & 0.09 & 0.08 & 0.02 & 0.08 & 0.24 & 0.43 & 0.71 & 1.08 & 1.45 \\
\hline$\sigma^{n w}$ & 0.04 & 0.08 & 0.12 & 0.18 & 0.24 & 0.30 & 0.38 & 0.46 & 0.53 & 0.61 \\
\hline$R^{2}$ & 0.00 & 0.00 & 0.00 & 0.00 & 0.00 & 0.01 & 0.01 & 0.03 & 0.05 & 0.08 \\
\hline \multirow[t]{2}{*}{$p-v a l$} & 0.21 & 0.27 & 0.34 & 0.44 & 0.38 & 0.27 & 0.19 & 0.11 & 0.05 & 0.02 \\
\hline & \multicolumn{10}{|c|}{ Panel B: 1926-2002 } \\
\hline & \multicolumn{10}{|c|}{ Sub-panel 1: Collateral Measure: Mortgages mymo } \\
\hline$b$ & 0.14 & 0.28 & 0.39 & 0.47 & 0.71 & 1.05 & 1.50 & 2.00 & 2.51 & 3.04 \\
\hline$\sigma^{n w}$ & 0.04 & 0.07 & 0.11 & 0.15 & 0.19 & 0.24 & 0.29 & 0.34 & 0.39 & 0.44 \\
\hline$R^{2}$ & 0.02 & 0.03 & 0.04 & 0.03 & 0.06 & 0.12 & 0.18 & 0.24 & 0.30 & 0.33 \\
\hline \multirow[t]{2}{*}{$p-v a l$} & 0.11 & 0.11 & 0.11 & 0.13 & 0.09 & 0.06 & 0.03 & 0.02 & 0.01 & 0.00 \\
\hline & \multicolumn{10}{|c|}{ Sub-panel 2: Collateral Measure: Residential Wealth myrw } \\
\hline$b$ & 0.09 & 0.13 & 0.11 & 0.03 & 0.08 & 0.24 & 0.44 & 0.68 & 0.91 & 1.15 \\
\hline$\sigma^{n w}$ & 0.04 & 0.07 & 0.12 & 0.17 & 0.23 & 0.31 & 0.40 & 0.49 & 0.59 & 0.70 \\
\hline$R^{2}$ & 0.01 & 0.01 & 0.00 & 0.00 & 0.00 & 0.01 & 0.02 & 0.03 & 0.04 & 0.05 \\
\hline \multirow[t]{2}{*}{$p-v a l$} & 0.20 & 0.26 & 0.34 & 0.44 & 0.41 & 0.33 & 0.25 & 0.17 & 0.13 & 0.09 \\
\hline & \multicolumn{10}{|c|}{ Sub-panel 3: Collateral Measure: Fixed Assets $m y f a$} \\
\hline$b$ & 0.06 & 0.04 & -0.08 & -0.17 & -0.09 & 0.11 & 0.41 & 0.69 & 0.86 & 1.02 \\
\hline$\sigma^{n w}$ & 0.04 & 0.08 & 0.13 & 0.18 & 0.24 & 0.31 & 0.39 & 0.49 & 0.59 & 0.72 \\
\hline$R^{2}$ & 0.00 & 0.00 & 0.00 & 0.00 & 0.00 & 0.00 & 0.01 & 0.02 & 0.02 & 0.03 \\
\hline$p-v a l$ & 0.34 & 0.43 & 0.57 & 0.62 & 0.55 & 0.43 & 0.29 & 0.20 & 0.17 & 0.14 \\
\hline
\end{tabular}


Table IV

Long-Horizon Predictability Regressions

The results are for the regression $r_{t+K}^{s p_{i, j}}=b_{0}+b_{m y} \widetilde{m y}{ }_{t}+\epsilon_{t+K}$, where $r_{t+K}^{s p_{i, j}, K}$ is the spread in log $K$-period holding returns for two extremum portfolios $i$ and $j$ formed on the basis of the six Fama-French Benchmark Portfolios (two independent sorts, 2 by size and 3 by book-to-market). Panel A reports results for the mortgage-based collateral measure mymo, panel $\mathrm{B}$ for the measure based on residential wealth myrw and panel $\mathrm{C}$ for the measure based on fixed assets $m y f a$. The housing collateral ratio is rescaled so that it lies between 0 and 1 and measures collateral scarcity. The first row of each pane reports least squares estimates for $b=b_{m y}$. Newey-West HAC standard errors $\sigma^{n w}$ are reported in the second row of each panel. The standard errors correct for serial correlation of order $K$, where $K$ is the holding period. The third row reports the $R^{2}$ for this OLS regression. The fourth row of each panel reports the p-value of the null hypothesis of no predictability, obtained by bootstrap. The estimation results are for 1927-2002.

\begin{tabular}{|c|c|c|c|c|c|c|c|c|c|c|}
\hline Horizon $K$ & 1 & 2 & 3 & 4 & 5 & 6 & 7 & 8 & 9 & 10 \\
\hline & \multicolumn{10}{|c|}{ Panel A: Collateral Measure: Mortgages mymo } \\
\hline & \multicolumn{10}{|c|}{ Spread: Small Value minus Small Growth } \\
\hline$b$ & 0.32 & 0.56 & 0.75 & 0.93 & 1.04 & 1.10 & 1.07 & 0.99 & 0.84 & 0.69 \\
\hline$\sigma^{n w}$ & 0.03 & 0.06 & 0.09 & 0.13 & 0.16 & 0.19 & 0.22 & 0.24 & 0.26 & 0.28 \\
\hline$R^{2}$ & 0.12 & 0.14 & 0.14 & 0.18 & 0.16 & 0.14 & 0.12 & 0.09 & 0.06 & 0.04 \\
\hline \multirow[t]{2}{*}{$p-v a l$} & 0.00 & 0.01 & 0.02 & 0.02 & 0.03 & 0.04 & 0.06 & 0.08 & 0.14 & 0.19 \\
\hline & \multicolumn{10}{|c|}{ Spread: Big Value minus Big Growth } \\
\hline$b$ & 0.21 & 0.42 & 0.61 & 0.73 & 0.79 & 0.86 & 0.93 & 0.90 & 0.77 & 0.57 \\
\hline$\sigma^{n w}$ & 0.03 & 0.06 & 0.10 & 0.14 & 0.17 & 0.21 & 0.25 & 0.29 & 0.33 & 0.37 \\
\hline$R^{2}$ & 0.05 & 0.09 & 0.12 & 0.11 & 0.10 & 0.10 & 0.10 & 0.08 & 0.05 & 0.02 \\
\hline \multirow[t]{3}{*}{$p-v a l$} & 0.03 & 0.02 & 0.03 & 0.04 & 0.06 & 0.06 & 0.08 & 0.10 & 0.15 & 0.22 \\
\hline & \multicolumn{10}{|c|}{ Panel B: Collateral Measure: Residential Wealth myrw } \\
\hline & \multicolumn{10}{|c|}{ Spread: Small Value minus Small Growth } \\
\hline$b$ & 0.28 & 0.46 & 0.60 & 0.73 & 0.79 & 0.82 & 0.78 & 0.70 & 0.54 & 0.41 \\
\hline$\sigma^{n w}$ & 0.03 & 0.06 & 0.09 & 0.12 & 0.15 & 0.17 & 0.19 & 0.22 & 0.24 & 0.25 \\
\hline$R^{2}$ & 0.10 & 0.10 & 0.10 & 0.12 & 0.10 & 0.08 & 0.07 & 0.05 & 0.03 & 0.01 \\
\hline$p-v a l$ & 0.01 & 0.01 & 0.02 & 0.03 & 0.04 & 0.06 & 0.09 & 0.13 & 0.20 & 0.26 \\
\hline \multicolumn{11}{|c|}{ Spread: Big Value minus Big Growth } \\
\hline$b$ & 0.23 & 0.43 & 0.60 & 0.70 & 0.77 & 0.85 & 0.98 & 1.02 & 0.98 & 0.88 \\
\hline$\sigma^{n w}$ & 0.03 & 0.06 & 0.10 & 0.13 & 0.15 & 0.18 & 0.20 & 0.23 & 0.26 & 0.29 \\
\hline$R^{2}$ & 0.06 & 0.10 & 0.13 & 0.11 & 0.10 & 0.10 & 0.12 & 0.11 & 0.09 & 0.06 \\
\hline$p-v a l$ & 0.02 & 0.02 & 0.03 & 0.04 & 0.06 & 0.07 & 0.06 & 0.08 & 0.10 & 0.13 \\
\hline \multicolumn{11}{|c|}{ Panel C: Collateral Measure: Fixed Assets $m y f a$} \\
\hline & \multicolumn{10}{|c|}{ Spread: Small Value minus Small Growth } \\
\hline$b$ & 0.37 & 0.54 & 0.59 & 0.66 & 0.74 & 0.76 & 0.68 & 0.52 & 0.34 & 0.17 \\
\hline$\sigma^{n w}$ & 0.04 & 0.07 & 0.10 & 0.14 & 0.17 & 0.20 & 0.23 & 0.26 & 0.28 & 0.30 \\
\hline$R^{2}$ & 0.11 & 0.09 & 0.06 & 0.06 & 0.06 & 0.05 & 0.03 & 0.02 & 0.01 & 0.00 \\
\hline$p-v a l$ & 0.00 & 0.02 & 0.05 & 0.07 & 0.08 & 0.10 & 0.14 & 0.22 & 0.30 & 0.38 \\
\hline & \multicolumn{10}{|c|}{ Spread: Big Value minus Big Growth } \\
\hline$b$ & 0.20 & 0.43 & 0.52 & 0.58 & 0.65 & 0.77 & 0.90 & 0.93 & 0.87 & 0.77 \\
\hline$\sigma^{n w}$ & 0.04 & 0.07 & 0.11 & 0.15 & 0.19 & 0.22 & 0.25 & 0.29 & 0.33 & 0.36 \\
\hline$R^{2}$ & 0.03 & 0.07 & 0.06 & 0.05 & 0.05 & 0.06 & 0.06 & 0.06 & 0.05 & 0.03 \\
\hline$p-v a l$ & 0.08 & 0.06 & 0.09 & 0.12 & 0.13 & 0.12 & 0.11 & 0.12 & 0.15 & 0.18 \\
\hline
\end{tabular}


Table V

\section{Annual Portfolio Returns 1927-2002.}

Time-series mean and standard deviation of gross portfolio returns. All returns are in excess of a 1 month T-bill return. The first two columns are value-weighted portfolios, the next two are equally-weighted portfolios and the last column denotes the value weighted portfolio average book-market ratio. All data are from Kenneth French for 1927-2002.

\begin{tabular}{cccccc}
\hline Asset & Mean & St. Dev & Mean & St. Dev. & B/M \\
\hline$R^{v w}$ & 7.9 & 20.9 & & & \\
\cline { 2 - 6 } S1B1 & 3.8 & 38.0 & 7.3 & 40.4 & 0.35 \\
S1B2 & 9.7 & 37.4 & 15.6 & 45.2 & 0.70 \\
S1B3 & 13.8 & 35.9 & 17.6 & 40.1 & 1.03 \\
S1B4 & 17.8 & 44.6 & 22.1 & 53.4 & 1.55 \\
S1B5 & 18.2 & 37.6 & 26.2 & 48.6 & 5.52 \\
S2B1 & 6.9 & 32.3 & 7.1 & 35.5 & 0.38 \\
S2B2 & 11.8 & 30.3 & 12.6 & 32.6 & 0.70 \\
S2B3 & 13.7 & 30.5 & 15.0 & 33.6 & 1.03 \\
S2B4 & 14.7 & 32.8 & 15.3 & 35.1 & 1.52 \\
S2B5 & 15.1 & 33.0 & 16.5 & 36.2 & 3.76 \\
S3B1 & 8.5 & 30.5 & 8.0 & 30.2 & 0.38 \\
S3B2 & 11.4 & 28.0 & 11.7 & 29.8 & 0.69 \\
S3B3 & 12.3 & 27.2 & 12.8 & 28.2 & 1.02 \\
S3B4 & 13.1 & 27.8 & 13.7 & 28.1 & 1.51 \\
S3B5 & 13.9 & 32.6 & 14.9 & 32.8 & 3.40 \\
\cline { 2 - 6 } S4B1 & 8.4 & 24.0 & 8.4 & 24.5 & 0.37 \\
S4B2 & 9.2 & 25.6 & 9.4 & 26.2 & 0.69 \\
S4B3 & 11.1 & 25.9 & 11.4 & 26.9 & 1.01 \\
S4B4 & 12.1 & 27.0 & 12.4 & 27.8 & 1.49 \\
S4B5 & 13.6 & 34.5 & 14.3 & 36.6 & 3.35 \\
\cline { 2 - 6 } S5B1 & 7.6 & 21.6 & 6.9 & 21.1 & 0.33 \\
S5B2 & 7.2 & 19.5 & 8.4 & 20.3 & 0.68 \\
S5B3 & 8.8 & 22.1 & 9.5 & 23.7 & 1.00 \\
S5B4 & 9.5 & 25.4 & 10.6 & 27.3 & 1.50 \\
S5B5 & 11.0 & 33.7 & 11.5 & 34.4 & 1.59 \\
\hline & & & & &
\end{tabular}


Table VI

\section{Cross-Sectional Results Collateral Model: 4 Assets.}

GMM Parameter estimates for the collateral model under separable preferences for 1926-2002. The estimates minimize the pricing errors on the market return, the T-bill return, a 10-year bond and a portfolio that goes long in value and short in growth $(\mathrm{hml})$. GMM estimates also impose 4 inequality conditions. The Chebyshev polynomial is first order: $\widetilde{\phi}(\cdot)=\theta_{1} \widetilde{m y}+\theta_{2} \widetilde{m y} \Delta \log c_{t+1} \cdot \gamma$ is the coefficient of relative risk aversion. The time discount factor $\delta$ is fixed at .95 in the estimation. The identity weighting matrix is used in the first stage. The Newey-West matrix with lag length 3 is used to compute the standard errors. The penalty parameter $c$ is varied between 10 and 500 . The last line reports the J-statistic and the p-value of the null that all pricing errors are zero.

\begin{tabular}{|c|c|c|c|c|c|c|c|c|c|c|c|}
\hline \multirow{3}{*}{$\begin{array}{c}\text { Parameters } \\
\hat{\gamma}\end{array}$} & \multicolumn{11}{|c|}{ Penalty Parameter $c$} \\
\hline & 10 & 15 & 20 & 30 & 40 & 60 & 80 & 100 & 150 & 300 & 500 \\
\hline & 23.48 & 13.23 & 8.83 & 5.62 & 4.13 & 2.84 & 2.23 & 1.84 & 1.24 & 1.24 & 1.24 \\
\hline s.e. & $(16.32)$ & $(9.34)$ & $(5.79)$ & $(4.40)$ & $(3.46)$ & $(2.67)$ & $(2.52)$ & $(5.52)$ & $(.78)$ & $(.75)$ & $(.72)$ \\
\hline$\hat{\theta_{1}}$ & .13 & .18 & .24 & .34 & .44 & .62 & .77 & .92 & 1.34 & 1.34 & 1.34 \\
\hline s.e. & $(.05)$ & $(.09)$ & $(.14)$ & $(.25)$ & $(.36)$ & $(.59)$ & $(.880$ & $(2.66)$ & $(.74)$ & $(.71)$ & $(.68)$ \\
\hline$\hat{\theta_{2}}$ & -.34 & -.60 & -.90 & -1.42 & -1.93 & -2.80 & -3.56 & -4.30 & -6.41 & -6.40 & -6.39 \\
\hline s.e. & $(.39)$ & $(.74)$ & $(1.09)$ & $(1.89)$ & $(2.68)$ & $(4.20)$ & $(6.00)$ & $(15.16)$ & $(4.14)$ & $(4.05)$ & $(3.96)$ \\
\hline$J$ & 31.56 & 9.68 & 3.83 & 1.61 & 1.16 & .94 & .89 & .89 & .79 & .40 & .27 \\
\hline$p$ & .000 & .0847 & .5748 & .8999 & .9487 & .9671 & .9729 & .9708 & .9779 & .9953 & .9982 \\
\hline
\end{tabular}


Table VII

\section{Cross-Sectional Results Collateral Model: 7 Assets.}

GMM Parameter estimates for the collateral model for 1926-2002. The estimates minimize the pricing errors on the market return, the T-bill return, a 10-year bond and the 4 extremum size and value portfolios. The estimation also imposes 7 inequality conditions. The left panel imposes separability by fixing $\epsilon$ at 0 , wile the left panel fixes $\epsilon$ at .85 . In column 1 and $4, \widetilde{\phi}(\cdot)$ is a first-order, in columns 2 and 5 a second order, and in columns 3 and 6 a third order Chebychev polynomial. The penalty parameter $c$ is 100 (columns 1), 12 (column 2), 11 (column 3), 300 (column 4), 2 (columns 5 and 6). The time discount factor $\delta$ is fixed at .95 in the estimation. The identity weighting matrix is used in the first stage, the Newey-West matrix with lag length 3 is used to compute standard errors.

\begin{tabular}{|c|c|c|c|c|c|c|}
\hline \multirow[b]{3}{*}{ Parameters } & \multicolumn{3}{|c|}{ Separability } & \multicolumn{3}{|c|}{ Non-Separability } \\
\hline & \multicolumn{3}{|c|}{ Polynomial Order } & \multicolumn{3}{|c|}{ Polynomial Order } \\
\hline & 1 & 2 & 3 & 1 & 2 & 3 \\
\hline$\hat{\gamma}$ & 4.78 & 4.96 & 4.67 & 2.07 & 1.35 & 1.35 \\
\hline s.e. & {$[1.72]$} & {$[1.68]$} & {$[1.58]$} & {$[.32]$} & {$[.19]$} & {$[.20]$} \\
\hline$\hat{\theta_{1}}$ & .37 & .63 & -.31 & -.15 & 7.31 & .44 \\
\hline s.e. & {$[.31]$} & {$[3.15]$} & {$[2.77]$} & {$[2.43]$} & {$[3.96]$} & {$[6.78]$} \\
\hline$\hat{\theta_{2}}$ & -2.00 & -1.93 & -6.61 & -5.16 & -8.14 & 6.44 \\
\hline s.e. & {$[.92]$} & {$[.85]$} & [13.46] & {$[1.78]$} & {$[4.87]$} & {$[7.40]$} \\
\hline$\hat{\theta_{3}}$ & & .33 & -.77 & -3.67 & 3.63 & .23 \\
\hline s.e. & & {$[4.05]$} & {$[3.16]$} & {$[8.31]$} & [28.37] & [10.14] \\
\hline$\hat{\theta_{4}}$ & & & -1.69 & & -.92 & -6.59 \\
\hline s.e. & & & {$[5.26]$} & & [19.73] & {$[5.83]$} \\
\hline$\hat{\theta_{5}}$ & & & & & 7.56 & 6.53 \\
\hline s.e. & & & & & [ 14.21] & {$[3.13]$} \\
\hline$\hat{\theta_{6}}$ & & & & & & 7.53 \\
\hline s.e. & & & & & & {$[7.95]$} \\
\hline$\hat{\theta_{7}}$ & & & & & & -.70 \\
\hline s.e. & & & & & & [13.37] \\
\hline$J$ & 33.68 & 110.37 & 56.31 & 14.18 & 60.36 & 54.15 \\
\hline$p$ & .0000 & .0000 & .0000 & .1671 & .0000 & .0000 \\
\hline
\end{tabular}


Table VIII

\section{Average Pricing Errors, Non-Linear Collateral Model.}

Average pricing errors implied by the GMM estimations with 7 assets (see Table VII). GMM t-stats are in parentheses. The Coll-CAPM pricing errors pertain to the model with first order polynomials only. Coll-CAPM 1 is the model with separability, Coll-CAPM 2 is under non-separability, while Coll-CAPM 3 adds a lagged consumption growth term as a factor in $\widetilde{\phi}(\cdot)$. The coefficient estimates for 2 and 3 are not reported. The errors for the inequality restrictions are not reported. The penalty parameter $c$ is 100,300 and 12 in columns 3,4 and 5 respectively.

\begin{tabular}{cccccc}
\hline Test Asset & CCAPM & H-CAPM & Coll-CAPM 1 & Coll-CAPM 2 & Coll-CAPM 3 \\
\hline$R^{f}$ & -.069 & -.057 & .016 & .006 & .015 \\
$(t-$ stat $)$ & $(-3.11)$ & $(-3.78)$ & $(.68)$ & $(.30)$ & $(3.38)$ \\
$R^{\text {vw }}$ & -.016 & -.000 & -.010 & -.002 & -.010 \\
$(t-$ stat $)$ & $(-0.85)$ & $(-.04)$ & $(-.73)$ & $(-.25)$ & $(-1.38)$ \\
$R^{S 1 B 1}$ & -.060 & -.042 & -.017 & .009 & -.011 \\
$(t-$ stat $)$ & $(-1.53)$ & $(-1.68)$ & $(-.19)$ & $(.23)$ & $(-.78)$ \\
$R^{\text {S1B5 }}$ & .070 & .078 & .042 & .024 & .043 \\
$(t-$ stat $)$ & $(1.83)$ & $(-3.44)$ & $(1.71)$ & $(.39)$ & $(1.42)$ \\
$R^{\text {S5B1 }}$ & -.021 & -.001 & -.021 & -.007 & -.021 \\
$(t-$ stat $)$ & $(-1.00)$ & $(-.09)$ & $(-1.58)$ & $(-.25)$ & $(-1.56)$ \\
$R^{\text {S5B5 }}$ & .071 & .070 & .001 & -.003 & -.003 \\
$(t-$ stat $)$ & $(2.20)$ & $(3.76)$ & $(.01)$ & $(-.14)$ & $(-.18)$ \\
$R^{\text {bond }}$ & -.059 & -.045 & -.013 & -.029 & -.017 \\
$(t-$ stat $)$ & $(-2.72)$ & $(-2.73)$ & $(-.25)$ & $(-.88)$ & $(-2.98)$ \\
\hline
\end{tabular}




\section{Table IX}

\section{Cross-Sectional Results, Linear Factor Model.}

Estimation of the market prices of risk $\tilde{\lambda}$, using the Fama-MacBeth procedure for 1926-2002. The asset pricing factors are $\Delta \log \left(c_{t+1}\right)$ in row $1, \Delta \log \left(c_{t+1}\right)$ and $\Delta \log \left(\alpha_{t+1}\right)$ in row $2, \Delta \log \left(c_{t+1}\right), \widetilde{m y} t, \widetilde{m y} y_{t} \Delta \log \left(c_{t+1}\right)$ in rows 3-5 and $\Delta \log \left(c_{t+1}\right)$, $\Delta \log \left(\alpha_{t+1}\right), \widetilde{m} y_{t}, \widetilde{m} y_{t} \Delta \log \left(c_{t+1}\right)$ and $\widetilde{m} y_{t} \Delta \log \left(\alpha_{t+1}\right)$ in rows 6-8. The housing collateral variable is the mortgage-based mymo in rows 3 and 6 , the residential-wealth-based myrw in row 4 and 7 and the fixed-assets-based myfa in row 5 and 8. $m y$ is estimated with data from 1925-2002. OLS standard errors are in parenthesis, Shanken (1992) corrected standard errors are in brackets. The last column reports the $R^{2}$ and the adjusted $R^{2}$ just below it.

\begin{tabular}{cccccccc}
\hline Model & $\tilde{\lambda}_{0}$ & $\tilde{\lambda}_{c}$ & $\tilde{\lambda}_{\alpha}$ & $\tilde{\lambda}_{m y}$ & $\tilde{\lambda}_{m y . c}$ & $\tilde{\lambda}_{m y . \alpha}$ & $R^{2}$ \\
\hline 1 & 8.87 & 1.61 & & & & & $\mathbf{9 . 4}$ \\
CCAPM & $(2.55)$ & $(1.01)$ & & & & & 5.6 \\
& {$[2.77]$} & {$[1.18]$} & & & & & \\
\hline 2 & 6.90 & .51 & .55 & & & & $\mathbf{3 7 . 5}$ \\
HCAPM & $(2.31)$ & $(.88)$ & $(.24)$ & & & & 32.0 \\
& {$[2.60]$} & {$[1.08]$} & {$[.30]$} & & & & \\
\hline 3 & 4.22 & 1.94 & & -.03 & 2.23 & & $\mathbf{8 6 . 5}$ \\
Separable Prefs. & $(2.29)$ & $(1.05)$ & & $(.06)$ & $(.79)$ & & 84.6 \\
mymo & {$[3.31]$} & {$[1.58]$} & & {$[.09]$} & {$[1.17]$} & & \\
\hline 4 & 3.52 & 2.12 & & -.03 & 1.36 & & $\mathbf{8 7 . 8}$ \\
Separable Prefs. & $(2.25)$ & $(1.02)$ & & $(.03)$ & $(.47)$ & & 86.1 \\
myrw & {$[3.33]$} & {$[1.58]$} & & {$[.05]$} & {$[.72]$} & & \\
\hline 5 & 2.81 & .97 & & -.00 & .66 & & $\mathbf{7 3 . 3}$ \\
Separable Prefs. & $(2.27)$ & $(.94)$ & & $(.02)$ & $(.35)$ & & 69.7 \\
myfa & {$[2.93]$} & {$[1.28]$} & & {$[.03]$} & {$[.47]$} & & \\
\hline 6 & 2.87 & 2.59 & .11 & -.02 & 2.77 & .05 & $\mathbf{8 7 . 4}$ \\
Non-Sep. Prefs. & $(2.73)$ & $(.81)$ & $(.26)$ & $(.06)$ & $(.64)$ & $(.18)$ & 84.3 \\
$m y m o$ & {$[4.45]$} & {$[1.38]$} & {$[.44]$} & {$[.10]$} & {$[1.09]$} & {$[.30]$} & \\
\hline 7 & 3.62 & 2.30 & .25 & -.03 & 1.45 & .11 & $\mathbf{8 8 . 1}$ \\
Non-Sep. Prefs. & $(2.48)$ & $(.92)$ & $(.20)$ & $(.03)$ & $(.41)$ & $(.08)$ & 85.1 \\
$m y r w$ & {$[3.81]$} & {$[1.47]$} & {$[.33]$} & {$[.06]$} & {$[.65]$} & {$[.13]$} & \\
\hline 8 & 3.20 & 1.56 & -.05 & -.02 & .94 & .05 & $\mathbf{8 5 . 4}$ \\
Non-Sep. Prefs. & $(2.44)$ & $(1.01)$ & $(.21)$ & $(.02)$ & $(.38)$ & $(.06)$ & 81.7 \\
$m y f a$ & {$[4.11]$} & {$[1.75]$} & {$[.38]$} & {$[.04]$} & {$[.66]$} & {$[.11]$} & \\
\hline
\end{tabular}

Table X

Factor Loadings in Collateral CAPM.

Factor loadings $\theta$ implied by the Fama-MacBeth coefficient estimates for $\lambda$ reported in table IX. The left panel reports the $\theta$ estimates for the separable collateral model, the right panel for the non-separable model. The first row inverts the $\lambda$ estimates from row 3 in table IX (separable collateral model using mymo) and row 6 (non-separable collateral model using mymo). The row labelled myrw (myfa) does the same for rows 4 and 7 (5 and 8 ) of table IX.

\begin{tabular}{cccc|ccccc}
\hline & \multicolumn{4}{c}{ Separability } & \multicolumn{4}{c}{ Non-Separability } \\
\hline Collateral Measure & $\theta_{1}^{a}$ & $\theta_{1}^{c}$ & $\theta_{2}^{c}$ & $\theta_{1}^{a}$ & $\theta_{2}^{a}$ & $\theta_{1}^{c}$ & $\theta_{2}^{c}$ & $\theta_{3}^{c}$ \\
\hline Mortages mymo & 44.17 & 0.91 & 29.42 & 57.67 & 8.10 & 1.17 & 38.09 & 4.43 \\
Residential Wealth myrw & 35.59 & 41 & 12.68 & 39.04 & 5.91 & 0.44 & 13.85 & 1.66 \\
Fixed Assets myfa & 16.19 & 0.11 & 5.02 & 25.39 & 3.74 & 0.17 & 7.85 & 1.06 \\
\hline
\end{tabular}


Table XI

\section{Average Pricing Errors, Linear Collateral Model.}

Pricing errors from the cross-sectional Fama-MacBeth Regressions. The set of returns is the value weighted market return $R^{v w}$ and the 25 size and book-to-market portfolio returns. The second column reports errors from the consumption CAPM, the third from the three-factor Fama-French model and the last column reports average errors from the collateral CAPM with scaling variable myrw (residential-wealth-based collateral measure) and separability in preferences (line 4 in table IX). The last two rows report the square root of the average squared pricing errors (RMSE) and the $\chi^{2}$ statistic for the null hypothesis that all pricing errors are zero. The degrees of freedom are 25, 23 and 23 respectively. Three stars denote rejection of the null hypothesis at the 1 percent level, 2 stars at the 5 percent level and 1 star at the 10 percent level. The sample is $1926-2002$.

\begin{tabular}{|c|c|c|c|}
\hline Test Asset & CCAPM & Fama-French & Coll-CCAPM \\
\hline$R^{v w}$ & 2.97 & -.20 & .07 \\
\hline S1B1 & 7.97 & 3.96 & 1.79 \\
\hline S1B2 & 1.89 & 2.51 & 1.23 \\
\hline S1B3 & -1.01 & -1.08 & -.34 \\
\hline S1B4 & -7.10 & -2.07 & 1.53 \\
\hline S1B5 & -5.29 & -2.78 & -.62 \\
\hline S2B1 & 4.64 & 1.94 & 2.03 \\
\hline S2B2 & -.30 & -1.15 & -1.27 \\
\hline S2B3 & -2.65 & -1.23 & -.96 \\
\hline S2B 4 & -3.31 & -.79 & -1.14 \\
\hline S2B5 & -3.00 & -.08 & -1.72 \\
\hline S3B1 & 1.99 & -1.41 & 2.00 \\
\hline S3B2 & -.24 & -1.12 & .28 \\
\hline S3B3 & -.50 & -.62 & -.55 \\
\hline S3B4 & -1.28 & .03 & -1.40 \\
\hline S3B5 & -1.92 & 1.58 & .38 \\
\hline S4B1 & 1.65 & -2.54 & -1.25 \\
\hline $\mathrm{S} 4 \mathrm{~B} 2$ & .90 & .70 & .85 \\
\hline S4B3 & -.22 & .24 & -2.08 \\
\hline S4B4 & -1.18 & .64 & .62 \\
\hline S4B5 & -3.90 & -.11 & -2.38 \\
\hline S5B1 & 3.41 & -2.52 & -.07 \\
\hline S5B2 & 3.31 & .73 & -.21 \\
\hline S5B3 & 2.13 & .46 & -.59 \\
\hline S5B4 & 1.19 & 1.96 & -.10 \\
\hline S5B5 & -3.95 & -.86 & .10 \\
\hline RMSE & 3.27 & 1.61 & 1.21 \\
\hline$\chi^{2}$ & $72.1^{* * *}$ & $61.1^{* * *}$ & $35.1^{*}$ \\
\hline
\end{tabular}




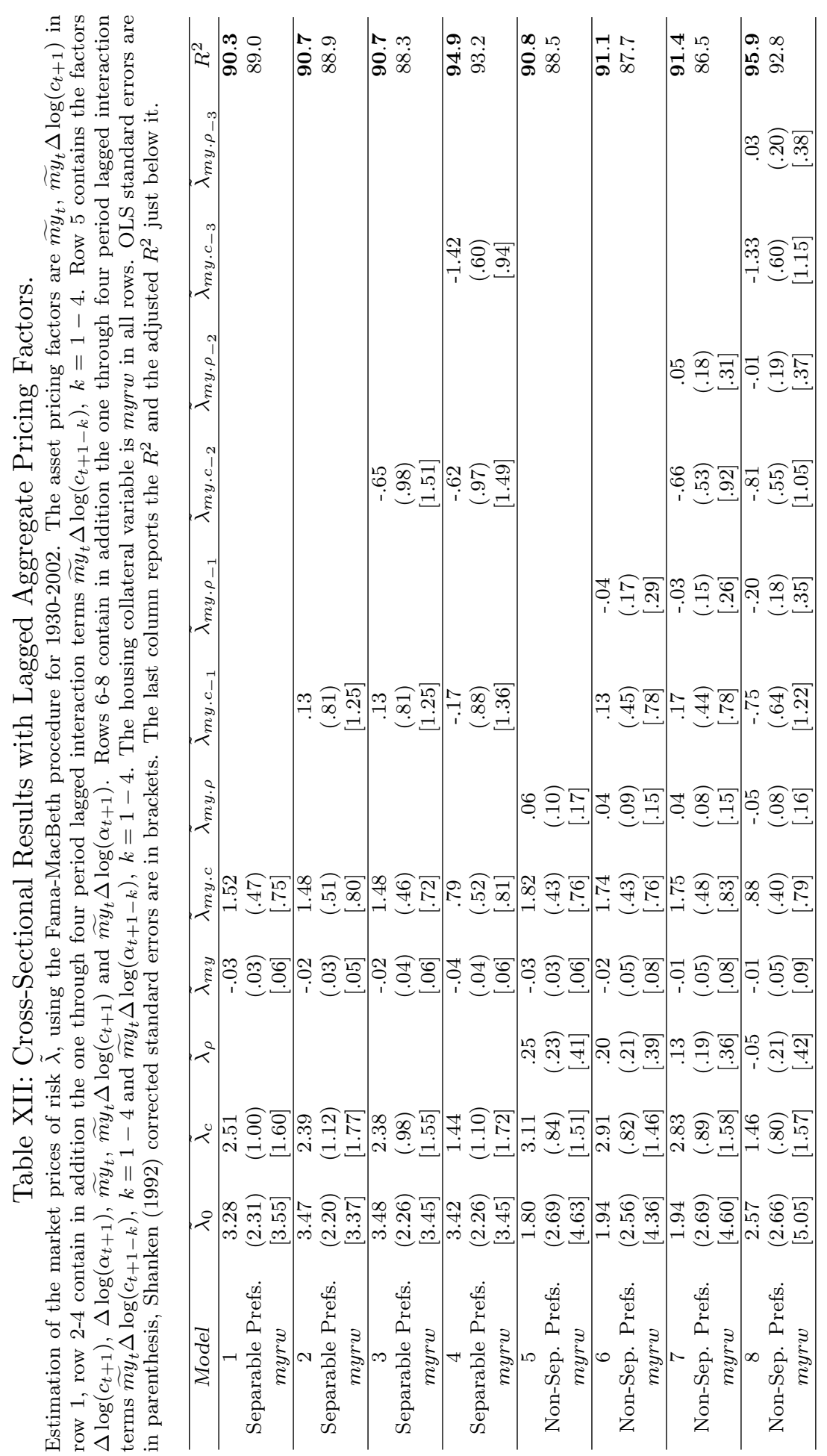


Table XIII

\section{Cross-Sectional Results, Fama-MacBeth, Quarterly Data.}

Estimation of the market prices of risk $\tilde{\lambda}$, using the Fama-MacBeth procedure for 1952.1-2002.4. The asset pricing factors are $\Delta \log \left(c_{t+1}\right)$ in row $1, \Delta \log \left(c_{t+1}\right)$ and $\Delta \log \left(\alpha_{t+1}\right)$ in row $2, \Delta \log \left(c_{t+1}\right), \widetilde{m y} t, \widetilde{m y} y_{t} \log \left(c_{t+1}\right)$ in rows 3-4 and $\Delta \log \left(c_{t+1}\right)$, $\Delta \log \left(\alpha_{t+1}\right), \widetilde{m y}{ }_{t}, \widetilde{m y} t_{t} \Delta \log \left(c_{t+1}\right)$ and $\widetilde{m y_{t}} \Delta \log \left(\alpha_{t+1}\right)$ in rows 6-7. The housing collateral variable is mymo in rows 3 and 6 and $m y f a$ in row 4 and 7. $m y$ is estimated with data from 1925-2002. The conditioning variable is the non-durable expenditure share $\alpha_{t}$ in rows 5 and 8 . In row 9 the asset pricing factors are $\Delta \log \left(c_{t+1}\right)$, cayt, and $\operatorname{cay}_{t} \Delta \log \left(c_{t+1}\right)$. cay is rescaled to ensure positivity: we use cay/std(cay) +3.5 . In row 10 the asset pricing factors are $R_{t+1}^{v w}, l c_{t}$, and $l c_{t} R_{t+1}^{v w}$. In line 11 the asset pricing factors are $R_{t+1}^{v w}, R_{t+1}^{S M B}$, and $R_{t+1}^{H M L}$. The OLS standard errors are in parenthesis. The last column reports the $R^{2}$ and the adjusted $R^{2}$ just below it.

\begin{tabular}{|c|c|c|c|c|c|c|c|}
\hline Model & $\tilde{\lambda}_{0}$ & $\tilde{\lambda}_{1}$ & $\tilde{\lambda}_{2}$ & $\tilde{\lambda}_{3}$ & $\tilde{\lambda}_{4}$ & $\tilde{\lambda}_{5}$ & $R^{2}$ \\
\hline \multirow[t]{2}{*}{$C C A P M$} & -.09 & 1.18 & & & & & 48.2 \\
\hline & $(.79)$ & $(.41)$ & & & & & {$[46.0]$} \\
\hline \multirow[t]{2}{*}{$H C A P M$} & -.60 & 1.49 & -.004 & & & & 50.1 \\
\hline & $(1.06)$ & $(.45)$ & $(.04)$ & & & & {$[45.7]$} \\
\hline \multirow{2}{*}{$\begin{array}{c}\text { Seperable Prefs. } \\
\text { mymo }\end{array}$} & -.58 & 1.32 & & .16 & .51 & & 67.7 \\
\hline & $(.81)$ & $(.43)$ & & $(.06)$ & $(.11)$ & & [63.3] \\
\hline \multirow{2}{*}{$\begin{array}{c}\text { Seperable Prefs. } \\
m y f a\end{array}$} & .43 & 1.36 & & -.001 & .11 & & 62.2 \\
\hline & $(.85)$ & $(.40)$ & & $(.01)$ & $(.04)$ & & {$[57.0]$} \\
\hline \multirow{2}{*}{$\begin{array}{c}\text { Seperable Prefs. } \\
\alpha\end{array}$} & .51 & 1.09 & & .006 & .90 & & 70.0 \\
\hline & $(.84)$ & $(.44)$ & & $(.002)$ & $(.36)$ & & {$[65.9]$} \\
\hline \multirow{2}{*}{$\begin{array}{l}\text { Non-Sep. Prefs. } \\
\text { mymo }\end{array}$} & .52 & .86 & .01 & .13 & .33 & -.02 & 78.8 \\
\hline & $(.74)$ & $(.29)$ & $(.03)$ & $(.05)$ & $(.09)$ & $(.01)$ & [73.5] \\
\hline \multirow{2}{*}{$\begin{array}{c}\text { Non-Sep. Prefs. } \\
\text { my fa }\end{array}$} & 1.38 & .66 & .01 & -.02 & .06 & .007 & 72.6 \\
\hline & $(.69)$ & $(.27)$ & $(.03)$ & $(.01)$ & $(.03)$ & $(.003)$ & {$[65.7]$} \\
\hline \multirow[t]{2}{*}{$\alpha_{t}-H C A P M$} & .52 & 1.03 & -.01 & 0.006 & .85 & -.01 & 71.7 \\
\hline & $(.67)$ & $(.34)$ & $(.03)$ & $(.002)$ & $(.28)$ & $(.02)$ & [64.6] \\
\hline \multirow[t]{2}{*}{ cayt $_{t}-C C A P M$} & 2.35 & .79 & & -.71 & 2.58 & & 66.6 \\
\hline & $(.97)$ & $(.30)$ & & $(.41)$ & (1.19) & & {$[62.1]$} \\
\hline \multirow[t]{2}{*}{$l c_{t}-C A P M$} & 2.88 & -1.17 & & .01 & -1.14 & & 64.3 \\
\hline & $(1.04)$ & $(1.17)$ & & $(.02)$ & $(1.69)$ & & [59.5] \\
\hline \multirow[t]{2}{*}{$F F$} & 3.78 & -2.07 & & .46 & 1.27 & & 74.0 \\
\hline & $(1.13)$ & $(1.27)$ & & $(.41)$ & $(.43)$ & & {$[70.5]$} \\
\hline
\end{tabular}


Table XIV

\section{Consumption Betas.}

Consumption betas are computed as $\beta_{t}=\beta_{c}+\beta_{c . m y} \widetilde{m y}{ }_{t}$. Good states are states where the residential-wealth-based collateral measure myrw is one standard deviation below zero and bad states are times where myrw is one standard deviation above zero (11 observations each). The second column reports the average consumption beta. The third and fourth column report the average consumption betas in good states and bad states respectively. The sample is $1926-2002$.

\begin{tabular}{cccc}
\hline Test Asset & All States & Good States & Bad States \\
\hline$R^{v w}$ & 1.56 & 0.89 & 2.34 \\
S1B1 & 1.48 & 1.27 & 1.76 \\
S1B2 & 2.28 & .47 & 4.34 \\
S1B3 & 3.20 & 1.70 & 4.95 \\
S1B4 & 3.39 & -.70 & 8.00 \\
S1B5 & 3.96 & .85 & 7.50 \\
S2B1 & 1.94 & .98 & 3.04 \\
S2B2 & 2.23 & 1.25 & 3.37 \\
S2B3 & 2.42 & .33 & 4.80 \\
S2B4 & 2.68 & .49 & 5.17 \\
S2B5 & 2.89 & .58 & 5.51 \\
S3B1 & 1.80 & .33 & 3.46 \\
S3B2 & 2.27 & .61 & 4.17 \\
S3B3 & 2.52 & 1.16 & 4.08 \\
S3B4 & 2.53 & .91 & 4.39 \\
S3B5 & 2.99 & .53 & 5.79 \\
S4B1 & 1.05 & .37 & 1.84 \\
S4B2 & 1.58 & .04 & 3.33 \\
S4B3 & 1.71 & .65 & 2.93 \\
S4B4 & 2.34 & .04 & 4.93 \\
S4B5 & 1.62 & -1.10 & 4.67 \\
S5B1 & 1.54 & 1.20 & 1.95 \\
S5B2 & 1.21 & .76 & 1.74 \\
S5B3 & 1.57 & .77 & 2.50 \\
S5B4 & 1.69 & .32 & 3.25 \\
S5B5 & 1.57 & -1.66 & 5.18 \\
\hline
\end{tabular}




\section{Table XV}

Comparison of 7 Linear Factor Models, 1926-2002.

Reported are the market prices of risk $\tilde{\lambda}$, estimated from the second stage Fama-MacBeth procedure. Row 1 is the CAPM with the value-weighted market return $R_{t+1}^{v w, e}$ as factor. Row 2 is the human capital augmented CAPM with factors $R_{t+1}^{v w, e}$ and $R_{t+1}^{h c, e}$, the return on human wealth. Row 3 is the scaled CAPM model, with scaling variable the labor income to consumption ratio $l c_{t}$. The other factors are $R_{t+1}^{v w, e}$ and $l c_{t} R_{t+1}^{v w, e}$. Row 4 is the consumption-CAPM with aggregate consumption growth as factor $\Delta \log \left(c_{t+1}\right)$. Row 5 is the scaled consumption CAPM with the consumption wealth ratio cay as scaling variable. The factors are $\Delta \log \left(c_{t+1}\right)$, cay, cay $t \Delta \log \left(c_{t+1}\right)$. Row 6 is the collateral model under separability, with factors $\Delta \log \left(c_{t+1}\right)$, myrw $w^{\max }-m y f a_{t}$, and $\left(m y r w^{\max }-m y f a_{t}\right) \Delta \log \left(c_{t+1}\right)$. Row 7 is the three-factor model with factors $R_{t+1}^{v w, e}$, the excess return associated with size $R_{t+1}^{s m b, e}$, and the excess return associated with value $R_{t+1}^{h m l, e}$. The second column gives the zero- $\beta$ return $\tilde{\lambda}_{0}$. OLS standard errors are in parenthesis, Shanken corrected standard errors are in brackets.

\begin{tabular}{cccccc}
\hline Model & $\tilde{\lambda}_{0}$ & $\tilde{\lambda}_{1}$ & $\tilde{\lambda}_{2}$ & $\tilde{\lambda}_{3}$ & $R^{2}$ \\
\hline 1 & -.30 & 9.35 & & & 28.3 \\
Static CAPM & $(4.02)$ & $(4.68)$ & & & 25.3 \\
Sharpe-Lintner & {$[4.40]$} & {$[5.65]$} & & & \\
\hline 2 & 2.24 & 7.13 & 3.91 & & 37.2 \\
Human Capital-CAPM & $(3.93)$ & $(4.58)$ & $(1.28)$ & & 31.7 \\
Jagannathan-Wang & {$[4.87]$} & {$[6.16]$} & {$[1.71]$} & & \\
\hline 3 & 1.47 & 7.48 & -.00 & 5.57 & 49.3 \\
lc-conditional CAPM & $(4.17)$ & $(4.82)$ & $(0.02)$ & $(4.99)$ & 42.4 \\
Santos-Veronesi & {$[5.49]$} & {$[6.42]$} & {$[0.03]$} & {$[6.62]$} & \\
\hline 4 & 8.88 & 1.61 & & & 9.4 \\
Static CCAPM & $(2.55)$ & $(1.01)$ & & & 5.6 \\
Breeden-Lucas & {$[2.77]$} & {$[1.18]$} & & & \\
\hline 5 & 3.88 & 2.68 & .02 & .42 & 86.2 \\
cay-conditional CCAPM & $(2.32)$ & $(1.05)$ & $(.02)$ & $(.30)$ & 84.3 \\
Lettau-Ludvigson & {$[3.84]$} & {$[1.80]$} & {$[.03]$} & {$[.53]$} & \\
\hline 6 & 3.52 & 2.12 & -.03 & 1.36 & 87.8 \\
Collateral-CAPM & $(2.25)$ & $(1.02)$ & $(.03)$ & $(.47)$ & 86.1 \\
this paper & {$[3.33]$} & {$[1.58]$} & {$[.05]$} & {$[.71]$} & \\
\hline 7 & 10.21 & -2.46 & 2.71 & 6.30 & 78.1 \\
Three-factor model & $(4.63)$ & $(5.17)$ & $(1.68)$ & $(1.74)$ & 75.1 \\
Fama-French & {$[5.24]$} & {$[6.32]$} & {$[2.52]$} & {$[2.56]$} & \\
\hline & & & & &
\end{tabular}


Table XVI

Model Comparison: Value and Size Spreads.

Table reports the realized spreads and the model predicted spreads on value (panel A) and size portfolios (panel B), implied by the Fama-MacBeth estimates of the market prices of risk. The first column reports the realized value spreads and size spreads, computed as the difference in sample means between the constituent portfolios. The second through fourth columns are the predicted spreads by the collateral CAPM, the standard consumption CAPM and the cay-CCAPM. The fifth through eighth column are the predicted spreads by the CAPM, Human capital augmented CAPM, $l c$-conditional CAPM and the Fama French three-factor model. We use annual data for 1926-2002.

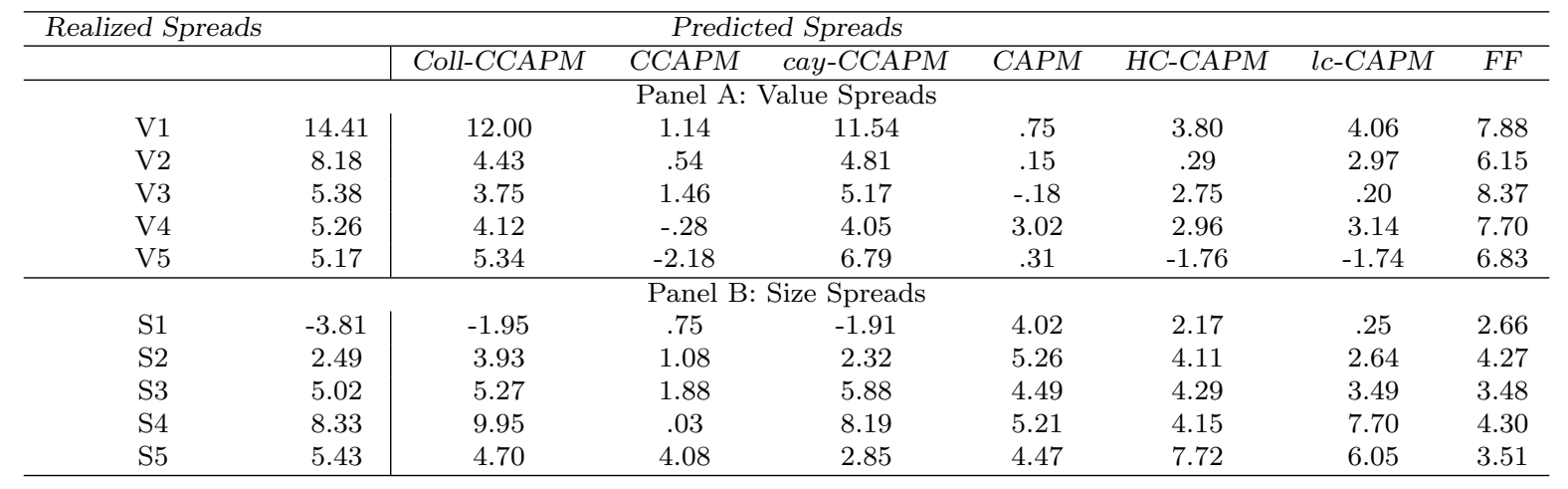

Table XVII

Dividend Share and the Housing Collateral Ratio.

Regression results for $\log \left(d_{t}\right)-\log \left(y_{t}\right)=b_{0}+b_{1} m y_{t}+\epsilon_{t}$, where $d_{t}$ is the nominal dividend on each of 10 portfolios sorted on book-to-market and $y_{t}$ is the nominal aggregate labor income plus transfers. The regressor is $m y m o$ in panel A, myr $w$ in panel B and myfa in panel C. The housing collateral ratios are estimated for the period 1889-2002. The dividend data are annual for 1952 to 1999, constructed from the monthly dividend yield provided by Bansal, Dittmar and Lundblad (2002). Each panel reports OLS estimates, their standard errors as well as the $R^{2}$.

\begin{tabular}{|c|c|c|c|c|c|c|c|c|c|c|}
\hline B/M Decile & B1 & $\mathrm{B} 2$ & B3 & $\mathrm{B} 4$ & B5 & $\mathrm{B} 6$ & $\mathrm{~B} 7$ & B8 & B9 & $\mathrm{B} 10$ \\
\hline & \multicolumn{10}{|c|}{ Panel A: Collateral Measure: Mortgages mymo } \\
\hline$b_{0}$ & -5.08 & -4.67 & -4.59 & -4.86 & -3.94 & -3.93 & -4.32 & -3.30 & -3.25 & -3.00 \\
\hline$\sigma\left(b_{0}\right)$ & $(0.12)$ & $(0.10)$ & $(0.09)$ & $(0.11)$ & $(0.08)$ & $(0.04)$ & $(0.04)$ & $(0.04)$ & $(0.06)$ & $(0.09)$ \\
\hline$b_{1}$ & 1.21 & .51 & .85 & 1.02 & .48 & .33 & .70 & .07 & -.63 & -1.12 \\
\hline$\sigma\left(b_{1}\right)$ & $(.30)$ & $(.26)$ & $(.23)$ & $(.29)$ & $(.21)$ & $(.10)$ & $(.10)$ & $(0.12)$ & $(0.14)$ & $(.23)$ \\
\hline \multirow[t]{2}{*}{$R^{2}$} & 0.266 & 0.074 & 0.225 & 0.207 & 0.100 & 0.179 & 0.490 & 0.007 & 0.304 & 0.344 \\
\hline & \multicolumn{10}{|c|}{ Panel B: Collateral Measure: Residential Wealth myrw } \\
\hline$b_{0}$ & -5.41 & -4.91 & -4.86 & -5.13 & -4.26 & -4.08 & -4.35 & -3.23 & -3.06 & -2.76 \\
\hline$\sigma\left(b_{0}\right)$ & $(0.10)$ & $(0.11)$ & $(0.08)$ & $(0.12)$ & $(0.06)$ & $(0.03)$ & $(0.05)$ & $(0.05)$ & $(0.04)$ & $(0.08)$ \\
\hline$b_{1}$ & 1.30 & .73 & .97 & 1.07 & .87 & .46 & .45 & -.09 & -.71 & -1.09 \\
\hline$\sigma\left(b_{1}\right)$ & $(.17)$ & $(.17)$ & $(.13)$ & $(.18)$ & $(.10)$ & $(.05)$ & $(.08)$ & $(0.08)$ & $(0.07)$ & $(.13)$ \\
\hline \multirow[t]{2}{*}{$R^{2}$} & 0.574 & 0.287 & 0.559 & 0.426 & 0.622 & 0.650 & 0.387 & 0.023 & 0.722 & 0.604 \\
\hline & \multicolumn{10}{|c|}{ Panel C: Collateral Measure: Fixed Assets $m y f a$} \\
\hline$b_{0}$ & -5.20 & -4.97 & -4.81 & -5.05 & -4.22 & -4.03 & -4.23 & -3.05 & -3.12 & -3.01 \\
\hline$\sigma\left(b_{0}\right)$ & $(0.91)$ & $(0.16)$ & $(0.15)$ & $(0.19)$ & $(0.12)$ & $(0.07)$ & $(0.09)$ & $(0.06)$ & $(0.09)$ & $(0.17)$ \\
\hline$b_{1}$ & .91 & .82 & .88 & .91 & .79 & .36 & .24 & -.41 & -.59 & -.62 \\
\hline$\sigma\left(b_{1}\right)$ & $(.34)$ & $(.26)$ & $(.25)$ & $(.32)$ & $(.21)$ & $(.11)$ & $(.15)$ & $(0.11)$ & $(0.16)$ & $(.29)$ \\
\hline$R^{2}$ & 0.133 & 0.171 & 0.217 & 0.147 & 0.241 & 0.186 & 0.049 & 0.236 & 0.233 & 0.093 \\
\hline
\end{tabular}




\section{A. Data Appendix}

Labor Income plus Transfers 1929-2002: Bureau of economic Analysis, NIPA Table 2.1, Aggregate labor income is the sum of wage and salary disbursements (line 2), other labor income (line 9), and proprietors' income with inventory valuation and capital consumption adjustments (line 10). Transfers is transfer payments to persons (line 16) minus personal contributions for social insurance (line 23). Prior to 1929, labor income plus transfers is 0.65 times nominal GDP. Nominal GDP Between 1929 and 2002, the ratio of labor income plus transfers to nominal GDP stays between .65 and .70 and equals .65 in 1929 and 1930. Nominal GDP for 1889-1928 is from Maddison (2001).

Number of Households For 1889-1945: Census (1976), series A335, A2, and A7. Household data are for 1880, 1890 1900, 1910, 1920, 1930, and 1940, while the population data are annual. In constructing an annual series for the number of households, we assume that the number of persons per household declines linearly in between the decade observations. For 1945-2002: U.S. Bureau of the Census, table HH-1, Households by Type: 1940: Present.

Price Indices All Items $\left(p^{a}\right)$ 1890-1912: Census (1976), Cost of Living Index (series L38). 1913-2002: CPI (BLS), base year is 1982-84. In parenthesis are the last letters of the BLS code. All codes start by CUUR0000S. Total price index $\left(p^{a}\right)$ : All items (code A0). Shelter $\left(p^{h}\right)$ : Item rent of primary residence (code EHA). Food $\left(p^{c}\right)$ 1913-2002: Item food (code AF1). Apparel ( $\left.p^{a p p}\right)$ 1913-2002: Item apparel (code AA).

\section{Aggregate Consumption}

Total Consumption Expenditures $C$ 1909-1928: Census (1976), Total Consumption Expenditures (series G470). The observations are for 1909, 1914, 1919, 1921, 1923, 1925, and 1927. For 1929-2002: Bureau of economic Analysis, NIPA table 2.2. Total Consumption expenditures is personal consumption expenditures (line 1).

Housing Services Consumption $C_{\text {rent }}$ 1909-1928: Census (1976), Rent and Imputed Rent (series G477). The observations are for 1909, 1914, 1919, 1921, 1923, 1925, and 1927. For 1929-2002: Bureau of economic Analysis, NIPA table 2.2. Housing services consumption $H$ is nominal consumption on housing services (line 14).

Food Consumption $C_{\text {food }}$ 1909-1928: Census (1976), Food (series G471 + G472 + G473). The observations are for 1909, 1914, 1919, 1921, 1923, 1925, and 1927. For 1929-2002: Bureau of economic Analysis, NIPA table 2.2. Nominal consumption of food (line 7).

Apparel Consumption $C_{\text {cloth }}$ For 1909-1928: Census (1976), Apparel (series G474). The observations are for 1909, 1914, 1919, 1921, 1923, 1925, and 1927. For 1929-2002: Bureau of economic Analysis, NIPA table 2.2. Nominal consumption of clothing and shoes (line 8).

Housing Expenditure share $A$ It is computed in two ways. The nondurable consumption share $\alpha=$ $1-A$ 
First, for 1909-2002, the housing expenditure share is computed as rent and imputed rent divided by total consumption expenditures minus rent and imputed rent and minus apparel. The observations are for 1909, 1914, 1919, 1921, 1923, 1925, and 1927. The cell entries for 1920, 22, 24, 26, and 28 are the average of the adjacent cells. The corresponding measure for the nondurable consumption share is $\alpha_{1}=1-A_{1}$.

Second, for 1929-2002: The housing expenditure share is $A$ is nominal consumption on housing services (line 14) divided by nominal consumption of non-durables (line 6) and services (line 13) minus clothing and shoes (line 8). The corresponding measure for the nondurable consumption share is $\alpha_{2}=1-A_{2}$.

Real Per Household Consumption Growth $d c$ It is computed in two ways. First, for 19222002, we construct real nondurable consumption, as total consumption deflated by the all items CPI minus rent deflated by the rent component of the CPI minus clothes and shoes deflated by the apparel CPI component. Per household variables are obtained by dividing by the number of households. The missing data for 1924, 26, and 28 are interpolated using Mehra \& Prescott (1985) real per capita consumption growth. The growth rate $d c_{1}$ is the log difference multiplied by 100. Second, for 1930-2002, we define real nondurable and services consumption (NDS), as nondurable consumption deflated by the NIPA nondurable price index plus services deflated by the NIPA services price index minus housing services deflated by the NIPA housing services price index minus clothes and shoes deflated by the NIPA clothes and shoes price index. The basis of all NIPA price deflators is $1996=100$. They are not the same as the corresponding CPI components from the BLS. Per household variables are obtained by dividing by the number of households. The growth rate $d c_{2}$ is the log difference of $N D S$ multiplied by 100 .

Rental Price Growth $d \rho$ It is computed in two ways. First, for 1913-2002 we use the ratio of CPI rent component to the CPI food component: $\rho=\frac{p^{h}}{p^{c}}$. The growth rate $d \rho_{1}$ is the log difference multiplied by 100. Second, for 1930-2002, we construct nominal non-durable consumption (non-durables plus services excluding housing services and excluding clothes and shoes) and real non-durable consumption (where each item is separately deflated by its own NIPA price deflator, basis $1996=100$ ). The deflator for nondurable consumption is then the ratio of the nominal to the real non-durable consumption series. The relative rental price is then the ratio of the price deflator for housing services to the price deflator for nondurable consumption. The growth rate $d \rho_{2}$ is the log difference multiplied by 100 .

Financial Wealth In order to construct the consumption wealth ratio at annual frequency (Lettau and Ludvigson (2001)) we need a measure of financial wealth. For 1945-2002: Flow of Funds, Federal Reserve Board, Balance sheet of households and non-profit organizations (B.100). Line 8: Financial Asses (FL154090005.Q). For 1926-1945: Total deposits, all commercial banks, NBER Macro-history database (series 14145). We assume that the ratio of deposits to total wealth decreases slowly from .205 to .185 , its level in 1945 (FoF deposits series). 


\section{References}

Attanasio, Orazio P., \& Steven J. Davis, 1996, Relative wage movements and the distribution of consumption, The Journal of Political Economy 104, 1127-1262.

Backus, David, Patrick Kehoe, \& Finn Kydland, 1992, International real business cycles, Journal of Political Economy 100, 745-75.

Bansal, Ravi, Robert Dittmar, \& Chris Lundblad, 2002, Consumption, dividends, and the cross-section of expected returns, mimeo.

Blundell, Richard, Luigi Pistaferri, \& Ian Preston, 2002, Partial insurance, information and consumption dynamics, mimeo.

Brav, Alon, George M. Constantinides, \& Christopher C. Gezcy, 2002, Asset pricing with heterogeneous consumers and limited participation: Empirical evidence, Journal of Political Economy 110(4), 793-824.

Breeden, Douglas T., 1979, An intertemporal asset pricing model with stochastic consumption and investment opportunities, Journal of Financial Economics 7, 265-296.

Campbell, John Y., 1996, Understanding risk and return, The Journal of Political Economy 104, 298-345.

Campbell, John Y., 2000, Asset pricing at the millennium, Journal of Finance 55, 1515-1567.

Campbell, John Y., \& Robert J. Shiller, 1988, The dividend-price ratio and expectations of future dividends and discount factors, Review of Financial Studies 1, 195-228.

Census, Bureau, 1976, Historical Statistics of the United States, Colonial Times to 1970 (U.S. Department of Commerce).

Chapman, David, 1997, Approximating the asset pricing kernel, The Journal of Finance 52(4), 1383-1410.

Cocco, Joao, 2000, Hedging house price risk with incomplete markets, working Paper London Business School.

Cochrane, John H., 1991a, Production based asset pricing and the link between stock returns and macroeconomic fluctuations, Journal of Finance 46, 209-238.

Cochrane, John H., 1991b, A simple test of consumption insurance, The Journal of Political Economy 99, 957-976.

Cochrane, John H., 1996, A cross-sectional test of an investment based asset pricing model, The Journal of Political Economy 104, 572-621.

Cochrane, John H., 2001, Asset Pricing (Princeton University Press, Princeton, N.J.).

Cogley, Tim, 2002, Idiosyncratic risk and the equity premium: Evidence from the consumer expenditure survey, Journal of Monetary Economics 49, 309-334.

Constantinides, George M., \& Darrell Duffie, 1996, Asset pricing with heterogeneous consumers, Journal of Political Economy 104, 219-240.

Dunn, K., \& K. Singleton, 1986, Modeling the term structure of interest rates under nonseparable utility and durability of goods, Journal of Financial Economics 17, 769-799.

Eichenbaum, Martin, \& Lars Peter Hansen, 1990, Estimating models with intertemporal substitution using aggregate time series data, Journal of Business and Economic Statistics 8, 53-69. 
Fama, Eugene F., \& Kenneth R. French, 1988, Dividend yields and expected stock returns., Journal of Financial Economics 25, 23-49.

Fama, Eugene F., \& Kenneth R. French, 1992, The cross-section of expected stock returns, Journal of Finance 47, 427-465.

Fama, Eugene F., \& Kenneth R. French, 1993, Common risk factors in the returns on stocks and bonds, Journal of Financial Economics 33, 3-56.

Ferson, Wayne E., Shmuel Kandel, \& Robert F. Stambaugh, 1987, Tests of asset pricing with time-varying expected risk-premiums and market betas, Journal of Finance 42, 201-220.

Flavin, Marjorie, \& Takashi Yamashita, 2002, Owner-occupied housing and the composition of the household portfolio, American Economic Review 79, 345-362.

Hansen, Lars Peter, \& R. Jagannathan, 1991, Implications of security markets data for models of dynamic economies, Journal of Policitical Economy 99, 252-262.

Hansen, Lars Peter, \& Kenneth J. Singleton, 1983, Stochastic consumption, risk aversion, and the temporal behavior of asset returns, Journal of Political Economy 91, 249-265.

Hess, Gregory D., \& Kwanho Shin, 1998, Intranational business cycles in the united states, Journal of International Economics 44, 289-313.

Jagannathan, Ravi, \& Zhenyu Wang, 1996, The conditional capm and the cross-section of expected returns, The Journal of Finance 51, 3-53.

Johansen, Soren, \& Katarina Juselius, 1990, Maximum likelihood estimation and inference on cointegration with applications to the demand for money, Oxford Bulletin of Economics and Statistics 52, 169-210.

Judd, Kenneth, 1998, Numerical Methods in Economics. (The MIT Press, Cambridge, Massachusetts), first edition.

Kandel, Shmuel, \& Robert F. Stambaugh, 1995, Portfolio inefficiency and the cross-section of expected returns, Journal of Finance 50, 157-184.

Krueger, Dirk, \& Jesus Villaverde, 2001, Consumption and saving over the life cycle; how important are consumer durables?, working Paper Stanford University.

Kullmann, Cornelia, 2002, Real estate and its role in asset pricing, working Paper Columbia GSB.

Lamont, Owen, 1998, Earnings and expected returns, Journal of Finance 53, 1563-1587.

Lettau, Martin, \& Sydney C. Ludvigson, 2003, Measuring and modeling variation in the risk-return trade-off, in Yacine Ait-Sahalia \& Lars Peter Hansen, (eds.) Handbook of Financial Econometrics.

Lettau, Martin, \& Syndey Ludvigson, 2001a, Consumption, aggregate wealth and expected stock returns, The Journal of Finance 56, 815-849.

Lettau, Martin, \& Syndey Ludvigson, 2001b, Resurrecting the (c)capm: A cross-sectional test when risk premia are time-varying, The Journal of Political Economy 109, 1238-1287.

Li, Qing, Maria Vassalou, \& Yuhang Xing, 2002, An investment-growth asset pricing model, working Paper Columbia GSB. 
Lintner, John, 1965, Security prices, risk, and maximal gains from diversification, The Journal of Finance 20, 587-615.

Lucas, Robert E., 1978, Asset prices in an exchange economy, Econometrica 46, 1429-54.

Lustig, Hanno, 2001, The wealth distribution and aggregate risk, mimeo Stanford University.

Lustig, Hanno, \& Stijn VanNieuwerburgh, 2002, Housing collateral and consumption insurance across us regions, mimeo.

Lustig, Hanno, \& Stijn VanNieuwerburgh, 2003, A theory of housing collateral and risk premia, working Paper NYU Stern and University of Chicago.

Luttmer, Erzo, 1991, Asset Pricing in Economies with Frictions, Ph.D. thesis.

Maddison, Angus, 2001, The World Economy: A Millennial Perspective, Economic History Services (OECD, Paris).

Mankiw, N. G., 1986, The equity premium and the concentration of aggregate shocks, Journal of Financial Economics 17, 211-219.

Mehra, \& Edward Prescott, 1985, The equity premium: A puzzle., Journal of Monetary Economics 15, $145-161$.

Piazzesi, Monika, Martin Schneider, \& Selale Tuzel, 2002, Housing, consumption and asset pricing, mimeo.

Santos, Tano, \& Pietro Veronesi, 2001, Labor income and predictable stock returns, mimeo.

Shanken, Jay, 1992, On the estimation of beta-pricing models, The Review of Financial Studies 5, 1-33.

Stambaugh, Robert F., 1999, Predictive regressions, Journal of Financial Economics 54, 375-421.

Storesletten, K., C. Telmer, \& A. Yaron, 2003, Cyclical dynamics of idiosyncratic labor income risk, Journal of Political Economy forthcoming.

Whitelaw, Robert F., 1997, Time-varying sharpe ratios and market timing, mimeo, NYU Stern School of Business.

Yao, Rui, \& Harold H. Zhang, 2002, Optimal consumption and portfolio choices with risky housing and borrowing constraint, mimeo.

Yogo, Motohiro, 2003, A consumption-based explanation of the cross-section of expected stock returns, working Paper, Harvard University. 